\title{
ASSESSMENT OF TORSATRONS AS REACTORS
}

\author{
J. F. Lyon
}

S. L. Painter

Australian National University, Canberra, Australia

Date Published: December 1992

Prepared for the Office of Fusion Energy

Budget Activity No. AT $101014 \mathrm{Z}$

\author{
Prepared by \\ OAK RIDGE NATIONAL LABORATORY \\ Oak Ridge, Tennessee 37831-6285 \\ managed by \\ MARTIN MARIETTA ENERGY SYSTEMS, INC. \\ for the \\ U.S. DEPARTMENT OF ENERGY \\ under contract DE-AC05-84OR21400
}




\section{CONTENTS}

ABSTRACT ………………………………………………………… v

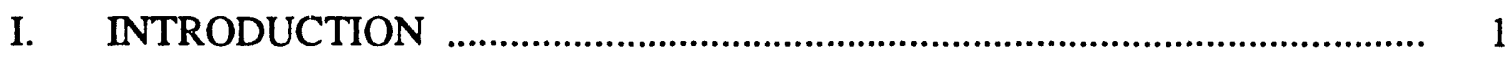

II. PROPERTIES OF STELLARATOR REACTORS …………………………... 1

II.A. Advantages of Stellarators as Reactors ................................................ 1

II.B. Stellarator Performance .......................................................................... $\quad 2$

II.C. Torsatrons and Modular Stellarators …………………………………... 3

II.D. Previous Stellarator Reactor Studies …………………………………..... 4

III. REACTOR OPTIMIZATION APPROACH ……………………………......... 4

III.A. Cost Assumptions ………………………………………………….. 5

III.B. Reactor Component Assumptions ........................................................... 6

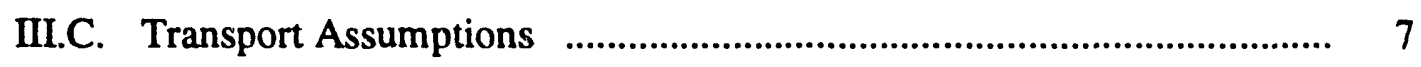

IV. SELECTION OF A REFERENCE CASE …………………………………..... 9

IV.A. Choice of a Reference Stellarator Configuration ………………............ 9

IV.B. Choice of Reference Assumptions ..................................................... 11

V. COMPARISON OF THE REFERENCE CASE WITH ARIES-I* ................. 12

VI. SENSITIVITY TO ASSUMPTIONS …………………………….................... 15

VI.A. Confinement and Blanket Assumptions ............................................ 15

VI.B. Coil Assumptions …………………………………………………….. 18

VI.C. Other Parameter Assumptions …………......................................... 20

VI.D. Coil Configuration ............................................................................... 21

VI.E. Scaling with Electrical Power Output ................................................... 21

VI.F. Effect of Modularization ................................................................... 22

VII. CU NCLUSIONS AND DISCUSSION ......................................................... 23

ACKNOWLEDGMENTS …………………………………………………..... 25

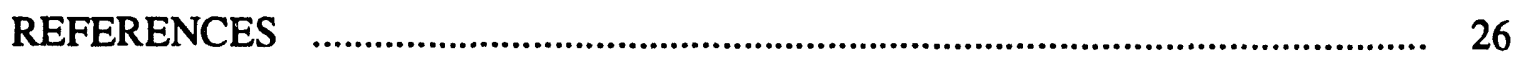




\begin{abstract}
Stellarators have significant operational advantages over tokamaks as ignited steady-state reactors because stellarators have no dangerous disruptions and no need for continuous current drive or power recirculated to the plasma, both easing the first wall, blanket, and shield design; less severe constraints on the plasma parameters and profiles; and better access for maintenance. This study shows that a reactor based on the torsatron configuration (a stellarator variant) could also have up to double the mass utilization efficiency (MUE) and a significantly lower cost of electricity (COE) than a conventional tokamak reactor (ARIES-I) for a range of assumptions. Torsatron reactors can have much smaller coil systems than tokamak reactors because the coils are closer to the plasma and they have a smaller cross section (higher average current density because of the lower magnetic field). The reactor optimization approach and the costing and component models are those used in the current stage of the ARIES-I tokamak reactor study. Typical reactor parameters for a $1-\mathrm{GW}(\mathrm{e})$ Compact Torsatron reactor example are major radius $R_{0}=6.6-8.8 \mathrm{~m}$, on-axis magnetic field $B_{0}=4.8-7.5 \mathrm{~T}, B_{\max }$ (on coils) $=16 \mathrm{~T}, \mathrm{MUE}=$ $140-210 \mathrm{~kW}(\mathrm{e}) /$ tonne, and COE (in constant 1990 dollars) $=67-79 \mathrm{mill} / \mathrm{kW}(\mathrm{e}) \mathrm{h}$. The results are relatively sensitive to assumptions on the level of confinement improvement and the blanket thickness under the inboard half of the helical windings but relatively insensitive to other assumptions.
\end{abstract}




\section{INTRU,UCTION}

Stellarator reactor studies are not as well developed as tokamak reactor studies. Although stellarators have the potential for leading to a better reactor, they lag behind tokamaks in their stage of development because of the greater resources that have been devoted to tokamaks and the wider range of possible stellarator configurations. The recent extensive Advanced Reactor Innovation and Evaluation Studies ${ }^{1}$ (ARIES) have explored the potential for improving the attractiveness of tokamak reactors. Our study applies for the first time the ARIES-I costing and component assumptions to the optimization of stellarator reactors. As background, the advantages of stellarators as reactors, stellarator performance relative to tokamaks, the two main types of stellarators, and previous stellarator reactor studies are discussed in Sec. II. The cost, reactor component, and transport assumptions used in the reactor optimization are summarized in Sec. III. The selection of a reference case is discussed in Sec. IV, and comparison of the results with the ARIES-I tokamak reactor studies is summarized in Sec. V. The sensitivity to various parameter choices and assumptions is discussed in Sec. VI. Finally, conclusions and further development of stellarators as reactors are discussed in Sec. VII.

\section{PROPERTIES OF STELLARATOR REACTORS}

\section{II.A. Advantages of Stellarators as Reactors}

There are serious concerns about the viability of tokamaks as attractive reactors. Tokamaks are not inherently steady-state devices. A large plasma current must be driven continuously with high efficiency or supplied by the bootstrap current. Current-drive efficiency is higher at lower density and higher temperature, just the opposite direction for edge conditions compatible with improved (H-mode) confinement and reduced erosion of divertor plates. The problem of simultaneously satisfying these conflicting constraints on the plasma parameters and their profiles is illustrated by the difficulty ${ }^{2}$ of obtaining a consistent operating point for the International Thermonuclear Experimental Reactor (ITER). If most of the plasma current is due to the bootstrap current, then the plasma must operate in the second stability regime to obtain an adequate volumeaveraged beta $\langle\beta\rangle$. To prevent serious damage to the first wall, blanket, and shields, tokamak reactors must operate without any current-driven disruptions, which imposes restrictions on their operating regime. In addition, improved energy confinement must be obtained without increased particle confinement to avoid a helium ash accumulation problem.

Stellarators offer a potential solution to these problems because they do not require a net plasma current (or the continuous power input to drive it). The magnetic field is created by currents flowing solely in external coils, resulting in inherently steady-state, disruption-free magnetic configurations with fewer constraints on the plasma and a wider range of configurations accessible for optimization and control. The type of stellarator configuration (torsatron ${ }^{3}$ ) used as an example here can have helical divertors ${ }^{4}$ outside the windings to reduce the power density on the divertor plates and, at the expense of a 
reduction in alpha-particle heating, ${ }^{5}$ a near-perpendicular loss region to eliminate helium ash accumulation. Pressure-gradient-driven (bootstrap) currents can be minimized to avoid undesired changes in the magnetic configuration by careful choice of the magnetic configuration properties. This has been demonstrated 6 in the Advanced Toroidal Facility (ATF) torsatron, ${ }^{7}$ where the bootstrap current was shown to follow the scaling predicted by neoclassical theory and the direction of the toroidal plasma current was changed from positive (as in a tokamak) to negative, in accordance with theory. Magnetic configurations have been found in which the beta limit increases at lower aspect ratio or in which ripple-induced transport is greatly reduced. Operation in the second stability regime (beta self-stabilization) for interchange modes has been obtained ${ }^{8}$ on ATF; this could lead to improved confinement with increasing $\beta$. In addition, stellarators have access from the small- $R$ side for easier maintenance.

\section{II.B. Stellarator Performance}

The parameters and physics understanding of present stellarators are similar to those obtained in tokamaks of comparable scale. In particular, stellarators and tokamaks have similar energy confinement time scaling, indicating that the underlying physics may be dominated by cornmon toroidal plasma physics rather than coil-geometry-specific effects. Figure 1 shows the measured energy confinement time $\tau_{E}$ versus that calculated
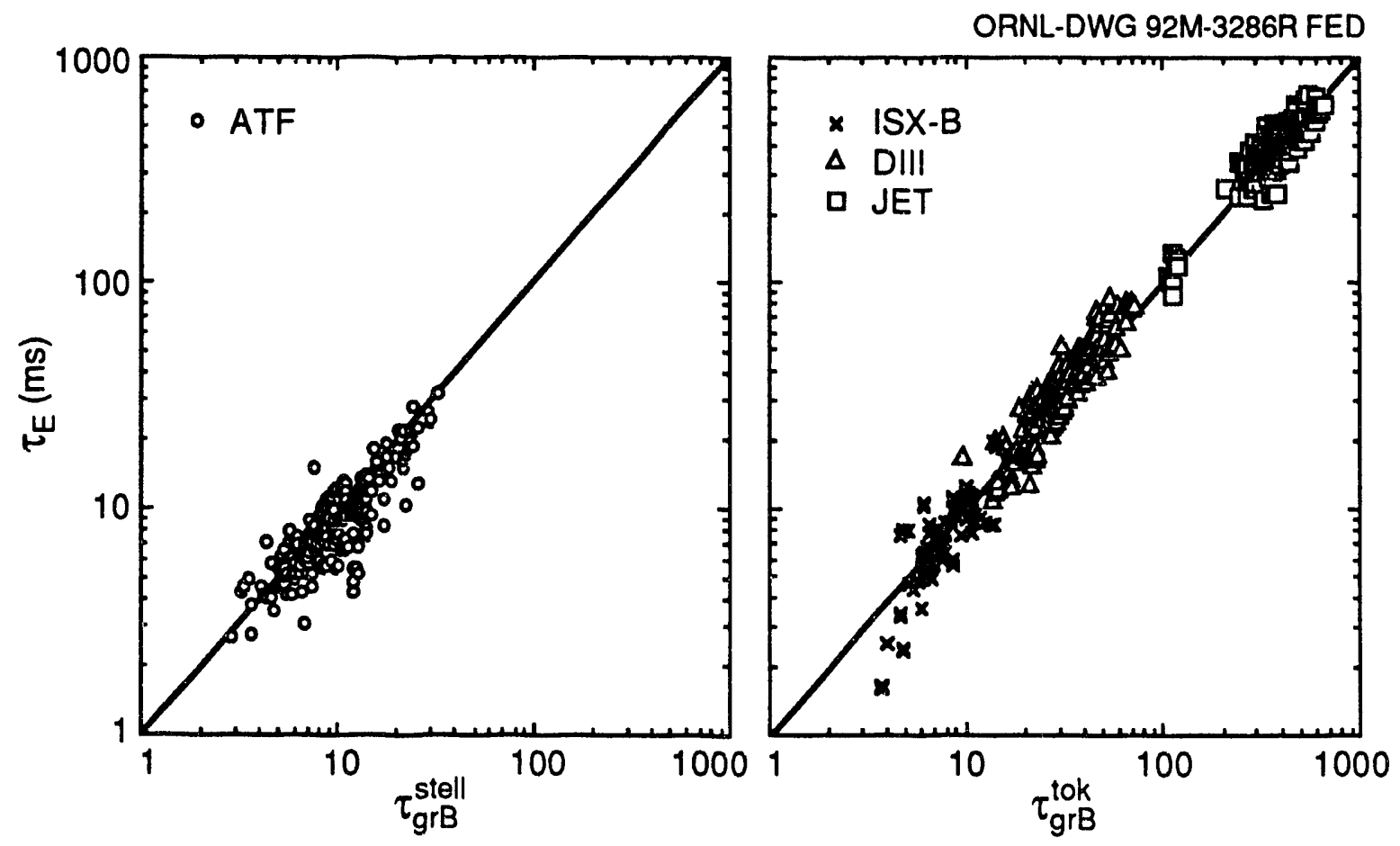

Fig. 1. Both stellarators (here, ATF) and L-mode tokamaks exhibit the same confinement scaling. 
for gyro-reduced Bohm scaling ${ }^{9}$ for ATF (Ref. 10) and for the tokamak L-mode data base, ${ }^{11}$ where

$$
\tau_{\mathrm{grB}} \text { stell }=0.25 B_{0}^{0.8} n^{0.6 p-0.6} a_{\mathrm{p}}{ }^{2.4} R_{0} 0.6 \mathrm{~A}_{\mathrm{i}}^{-0.2}
$$

for stellarators and

$$
\tau_{\mathrm{grB}}{ }^{\mathrm{tok}}=0.194 \mathrm{I}_{\mathrm{p}}^{0.8} n^{0.6 P}-0.6 a^{2.2} A_{\mathrm{p}}^{1.02} \mathrm{~A}_{\mathrm{i}}^{-0.2}
$$

for tokamaks using average tokamak quantities (plasma ellipticity $K=1.4$, average plasma aspect ratio $A_{\mathrm{p}} \equiv R_{0} / a_{\mathrm{p}}=3$, safety factor $q_{\mathrm{cyl}}=3$ ) to connect the tokamak plasma current $I_{\mathrm{p}}$ to the on-axis field $B_{0}$. Here $a_{\mathrm{p}}$ is the average radius of the noncircular (and nonaxisymmetric in stellarators) last closed magnetic surface, $a$ is the plasma minor radius (for tokamaks), $n$ is the line-averaged electron density (in $10^{20} \mathrm{~m}^{-3}$ ), $P$ is the absorbed heating power (in $M W$ ), and $A_{i}$ is the average ion mass ( $=2.5$ for the $D-T$ plasma). All other quantities are in SI units.

Present stellarators 12 are much smaller $\left(a_{\mathrm{p}}=0.2-0.27 \mathrm{~m}\right)$ than present tokamaks $\left(a_{\mathrm{p}}=0.85-1.62 \mathrm{~m}\right)$ and have not yet demonstrated adequate confinement and beta at parameters that can be extrapolated to the reactor regime. It is evident from Fig. 1 that the gap between the present performance and that needed for a reactor is much larger for stellarators than it is for tokamaks; typically, $\tau_{E}$ needis to increase by a factor of $\sim 100$ 200 for stellarators but only $\sim 5-10$ for tokamaks. Until larger $\left(a_{\mathrm{p}}=0.52-0.65 \mathrm{~m}\right)$ nextgeneration stellarators ${ }^{13,14}$ begin operation near the end of this decade, assessment of the reactor potential of stellarators must rely on reactor studies and results from present experiments.

\section{II.C. Torsatrons and Modular Stellarators}

The two main types of stellarator coil geometries are modular stellarators with a large number of nonplanar coils [similar to tokamak toroidal field (TF) coils] and torsatrons (called "heliotrons" in Japan) with helical windings. Both coil geometries lead to attractive steady-state reactor configurations. Torsatron reactors typically have moderate plasma aspect ratio $\left(A_{\mathrm{p}}=3.3-8\right.$ ), significant helical field ripple (up to $\sim 20 \%$ ), sufficient access between the windings for blankets and maintenance, and an external helical divertor between the windings. A reactor of this type is used in this paper to illustrate a self-consistent approach for stellarator optimization. Modular stellarators typically have larger plasma aspect ratio $\left(A_{\mathbf{p}} \sim 10\right)$, smaller helical field ripple, blankets between the plasma and the coils, and divertors located inside the coils. Stellarator reactors of this type are described by Grieger et al. 15 


\section{II.D. Previous Stellarator Reactor Studies}

Previous stellarator reactor studies were essentially of two types: parametric optimization studies of modular stellarator reactors that did not use modern stellarator physics, and more detailed reactor studies that were based on extrapolations of specific experiments. However, none of these studies has integrated the relevant physics, engineering, reactor component, and cost constraints in optimizing stellarator reactors.

Table I summarizes the main parameters from the principal stellarator reactor studies. Here $P_{\text {th }}$ is the thermal power produced and $\Gamma_{\mathrm{n}}$ is the neutron wall flux. The Heliotron I reactor concept ${ }^{16}$ is scaled from a modified Heliotron E-like configuration to reactor size with assumed values and profiles for the plasma parameters. The U-2MR (Ref. 17), ATR-2 (Ref. 18), and ASRA6C (Ref. 19) reactor concepts are also scaled to reactor size from existing experimental configurations, but their plasma behavior is calculated using one-dimensional (1-D) transport equations with electric-field-dependent stellarator transport coefficients. Compared to the ARIES tokamak reactors, ${ }^{20}$ these stellarator reactors have significantly larger $R_{0}(10-20 \mathrm{~m}$ versus $5.6-7.5 \mathrm{~m})$, lower $B_{0}(5 \mathrm{~T}$ versus 7.7-10.7 T), and higher $\langle\beta\rangle(4-8 \%$ versus $1.9-3.4 \%)$.

\section{REACTOR OPTIMIZATION APPROACH}

The reactor cost models and component assumptions are those employed in the ARIES-I tokamak reactor studies. ${ }^{20-22}$ This approach allows a more accurate relative

TABLE I

Major Device Parameters for Stellarator Reactors

\begin{tabular}{|c|c|c|c|c|}
\hline & $\begin{array}{c}\text { H-I } \\
(1986)\end{array}$ & $\begin{array}{l}\text { ATR-2 } \\
(1988)\end{array}$ & $\begin{array}{c}\text { U-2MR } \\
(1986)\end{array}$ & $\begin{array}{c}\text { ASRA6C } \\
(1986)\end{array}$ \\
\hline Origin & Kyoto, Japan & $\begin{array}{l}\text { Oak Ridge, } \\
\text { U.S.A. }\end{array}$ & $\begin{array}{l}\text { Kharkov, } \\
\text { Ukraine }\end{array}$ & $\begin{array}{l}\text { Garching, } \\
\text { Germany }\end{array}$ \\
\hline Type & $\ell=2$ torsatron & $\ell=2$ torsatron & $l=2$ torsatron & $\begin{array}{l}\text { Modular } \\
\text { stellarator }\end{array}$ \\
\hline Coil design & $\begin{array}{l}\text { NbTi, helical } \\
\text { jointed }\end{array}$ & $\mathrm{Nb}_{3} \mathrm{Sn}$, helical & $\begin{array}{l}\mathrm{Nb}_{3} \mathrm{Sn} \text {, helical } \\
+\mathrm{TF}\end{array}$ & $\begin{array}{l}\mathrm{Nb}_{3} \mathrm{Sn}, \\
\text { nonplanar TF }\end{array}$ \\
\hline$R_{0}(\mathrm{~m})$ & 16.0 & 10.5 & 15.0 & 20.0 \\
\hline$a_{c}(\mathrm{~m})$ & 3.0 & 3.3 & 3.8 & 4.6 \\
\hline$B_{0}(\mathrm{~T})$ & 5.0 & 5.0 & 5.0 & 5.3 \\
\hline$a_{\mathrm{p}}(\mathrm{m})$ & 2.0 & 2.3 & 1.6 & 1.6 \\
\hline$\langle\beta\rangle(\%)$ & 7.3 & 6.3 & 8.0 & 3.9 \\
\hline$P_{\text {th }}(\mathrm{GW})$ & 5.4 & 4.0 & 3.8 & 3.9 \\
\hline$\Gamma_{\mathrm{n}}\left(\mathrm{MW} / \mathrm{m}^{2}\right)$ & 3.1 & 2.7 & 4.0 & 1.5 \\
\hline
\end{tabular}


comparison of stellarators and tokamaks as reactors and is possible because of their general similarity. The models for the detailed component geometry and reactor performance constraints, however, are specialized for the example of a particular torsatron reactor because of specific differences between different types of stellarators and between stellarators and tokamaks. An assessment in which both the confinement concept and the cost models and component assumptions differed from those in tokamak reactor studies would be more difficult to interpret.

The quantity minimized in the optimization is the cost of electricity (COE). The masses of the individual reactor components are used to calculate the cost of the reactor core, using the cost models established for the ARIES studies. ${ }^{20-22}$ The expressions used for the other elements of the reactor cost and the COE are those used in the most recent ARIES-I study. ${ }^{23}$ The constraints chosen for the optimization are net electric power output $P_{\mathrm{E}}=1 \mathrm{GW},\langle\beta\rangle=6 \%$, and a set of helical winding constraints [radial room between the edge of the plasma and the center of the helical field (HF) winding on the inboard side, clearance between windings for access, transverse elongation of the helical winding $k \leq k_{\max }=3$, maximum magnetic field on the winding $B_{\max } \leq 16 \mathrm{~T}$ (versus $20 \mathrm{~T}$ for the ARIES-I reactor), and limits on the current density $j$ in the winding pack]. The optimization variables are those related to the device size $\left(R_{0}\right)$, the resulting plasma parameters (volume-averaged density $\langle n\rangle$, density-averaged temperature $\langle T\rangle$ ), and the magnetic field ( $B_{0}$ and the width and radial depth of the helical winding pack).

\section{III.A. Cost Assumptions}

This paper adopts the cost expressions and unit values used in Ref. 22, in which the ARIES-I reactor was recosted using the rules that evolved during the ARIES-III study, with some recent (through May 1992) improvements. ${ }^{23}$ The COE estimated for the 1-GW(e) ARIES-I tokamak reactor has evolved from $69 \mathrm{mill} / \mathrm{kW}(\mathrm{e}) \mathrm{h}$ in 1988 dollars (Ref. 24) without the level of safety assurance (LSA) factors ${ }^{25}$ appropriate to the lowactivation materials assumed, and $55 \mathrm{mill} / \mathrm{kW}(\mathrm{e}) \mathrm{h}$ with those credits, to $93 \mathrm{mill} / \mathrm{kW}(\mathrm{e}) \mathrm{h}$ in 1990 dollars (Ref. 26) without the LSA $=2$ credits, and $86 \mathrm{mill} / \mathrm{kW}(\mathrm{e}) \mathrm{h}$ with those credits. The May 1992 estimate is 81.4 mill/kW(e)h in 1990 dollars (Ref. 23) with the LSA $=2$ credits.

We recalculated the ARIES-I costs using the latest ARIES-I parameters to benchmark our calculations and to provide a more detailed comparison with our torsatron reactor calculations. The values obtained for "our" ARIES-I, which we designate ARIES-I*, are very close (a few tenths of a percent) to the values obtained in a May 1992 recalculation 23 of ARIES-I, as shown in Table II. The slight differences arise from the different approximations used in calculating the masses of the blankets and shields.

This study emphasizes the costs for a torsatron reactor relative to those for ARIES-I* and the robustness of the costs to different assumptions, rather than the absolute costs. As in the ARIES (and other tokamak) reactor studies, the costs assume "learning curve" credits of $\approx 50 \%$ associated with a "tenth-of-a-kind" production reactor. These credits, 
TABLE II

Comparison of ARIES-I and ARIES-I*

\begin{tabular}{|c|c|c|}
\hline & $\begin{array}{l}\text { ARIES-I } \\
\text { (Ref. 23) }\end{array}$ & $\begin{array}{c}\text { "Our" ARIES-I, } \\
\text { ARIES-I* }\end{array}$ \\
\hline \multicolumn{3}{|l|}{ Reactor equipment cost $(\mathrm{a})$} \\
\hline Blanket and first wall & 485.4 & 469.5 \\
\hline Shields & 202.7 & 214.6 \\
\hline Magnets & 365.4 & 365.4 \\
\hline Supplemental heating systems & 98.2 & 98.2 \\
\hline Primary structure and support & 58.6 & 58.6 \\
\hline Reactor vacuum systems & 21.5 & 20.8 \\
\hline Power supply, switching, storage & 52.5 & 52.5 \\
\hline Impurity control & 5.5 & 5.4 \\
\hline ECH breakdown system & 4.1 & 4.1 \\
\hline Total reactor equipment & 1293.7 & 1289.1 \\
\hline Total reactor plant equipment ${ }^{(a)}$ & 1632.5 & 1627.8 \\
\hline Total direct cost $(a)$ & 2322.9 & 2318.2 \\
\hline Total capital cost ${ }^{(a)}$ & 4481.9 & 4472.8 \\
\hline Total cost of electricity [mill/kW(e)h] & $81.4^{(b)}$ & 81.4 \\
\hline Mass power density $[\mathrm{kW}(\mathrm{e}) /$ tonne] & 100.1 & 99.3 \\
\hline
\end{tabular}

(a) In millions of constant 1990 dollars.

(b) After a reduction of $0.5 \mathrm{mill} / \mathrm{kW}(\mathrm{e}) \mathrm{h}$ to correct for a change in the calculation of the capital return and blanket/first wall replacement cost components of the COE.

plus the LSA $=2$ credits associated with low-activation materials, result in costs that are low compared to ITER-based cost estimates.

\section{III.B. Reactor Component Assumptions}

The study assumes the same level of technolngy development ("achievable in 20 years") as in the ARIES-I study (Ref. 22). The thicknesses, compositions, average mass densities, and unit costs for the first wall/blanket/reflector assembly and the neutron shielding are the same as those for ARIES-I. The same very-low-activation silicon carbide composite material is assumed for the structural material in the blanket and shield. The blanket has a global tritium breeding ratio of 1.18 , an energy multiplication factor of 1.3 , and a thickness of $0.67 \mathrm{~m}$ between the helical windings on the inboard side of the torus and $0.97 \mathrm{~m}$ on the outboard (large- $R$ ) side of the torus. However, the thickness of the blanket directly under the helical windings on the inboard (small- $R$ ) side of the torus has one of three values $(0,0.335 \mathrm{~m}$, or $0.67 \mathrm{~m})$, depending on the case of interest. This is not an option in a tokamak reactor because there is not enough room 
between the TF coils on the inboard side for a blanket, so the space under the TF coils on the inboard side must have the full $(0.67-\mathrm{m})$ inboard blanket thickness. The neutron shield has a thickness of $0.71 \mathrm{~m}$ everywhere on the inboard side of the torus and a thickness of $0.81 \mathrm{~m}$ on the outboard side, as in ARIES-I.

The coils, like those in ARIES-I, use $\mathrm{Nb}_{3} \mathrm{Sn}$ superconducting cables with a partially load-bearing $\mathrm{CuNb}$ stabilizer. The superconducting winding pack, which includes the superconducting cables, helium coolant paths, and structure, is assumed to have a rectangular cross section with transverse (mainly toroidal) elongation $k=w / h$, where $w$ and $h$ are its half-width and half-height. The maximum allowable current density $j_{\max }$ in the helical winding, averaged over the winding pack, is related to $B_{\max }$ by the relation used in the ARIES-I studies,

$$
j_{\max }=\frac{0.8 \sigma_{\text {allow }}-B_{\text {max }}{ }^{2} / \mu_{0}}{\left(\sigma_{\text {allow }}-\sigma_{\text {stab }}\right) / j_{\text {stab }}+\sigma_{\text {allow }} / j_{\text {sc }}+\left(B_{0} R_{0} / 4\right) \ln \left(R_{\text {outer }} / R_{\text {inner }}\right)} .
$$

This expression ${ }^{27}$ allows for different current densities in the superconductor $\left(j_{\mathrm{sc}}\right)$ and stabilizer $\left(j_{\text {stab }}\right)$, different stresses in the stabilizer $\left(\sigma_{\text {stab }}\right)$ and coil support structure $\left(\sigma_{\mathrm{alijw}}\right)$, and the use of $25 \%$ of the winding cross section for insulation and helium coolant channels. Here $R_{\text {inner }}$ and $R_{\text {outer }}$ are the average major radii of the inner and outer legs of the coils. The value of $B_{\max }$ is calculated from an expression 28 that gives an xcellent fit over a wide range of $k$ values to results obtained using the finite-element code MAGFOR (Ref. 29) with accurate helical winding trajectories. As in the ARIES-I studies, the volume of the coil support structure is half that of the coils.

The thermal particles and alpha particles exit from the plasma in a thin helical strip 30 between the helical windings. The divertor area required is calculated by dividing the total power to the divertor by $3 \mathrm{MW} \cdot \mathrm{m}^{-2}$, rather than using the ARIES-I assumption that the divertor plate area is $15 \%$ of the first wall area. The other engineering and materials assumptions are the same as those used in the ARIES-I studies. ${ }^{22}$

\section{III.C. Transport Assumptions}

A global energy confinement time $\tau_{E}$ is used to calculate the conduction power, rather than assuming that the conduction power is a fixed fraction (0.533) of the power in the plasma as in the ARIES-I studies. Unfortunately, different energy confinement scalings fit present stellarator data but scale differently to reactors: the Large Helical Device (LHD) scaling 31

$$
\tau_{E}^{\mathrm{LHD}}=0.17 R_{0} 0.75 a_{\mathrm{p}}{ }^{2} n^{0.69} B_{0} 0.84 P 0.58,
$$

an empirical fit to stellarator data; the gyro-reduced Bohm scaling [Eq. (1)], which is based on drift-wave theory; and the Lackner-Gottardi scaling, 32

$$
\tau_{E}^{\mathrm{LG}}=0.17 R_{0} a_{\mathrm{p}}{ }^{2} n^{0.6} B_{0} 0.8 P-0.6 \chi 0.4,
$$


which fits both tokamak (ASDEX) and stellarator (Wendelstein VII-A, Wendelstein VII-AS) data. Unlike the LHD scaling, the Lackner-Gottardi scaling and the gyroreduced Bohm scaling [Eq. (1)] are dimensionally correct; i.e., they are expressible in terms of dimensionless plasma parameters. In addition, they have the same functional dependence on the reactor parameters $R_{0}, B_{0}, n$, and $P$, differing only by an aspect-ratiodependent coefficient. For the torsatron reactor examples studied in this paper, $\tau_{E}{ }^{L G}$ is $0.95 \tau_{E}{ }^{\mathrm{grB}}$ if the $\mathrm{A}_{\mathrm{i}}-0.2$ term in Eq. (1) is neglected or $1.15 \tau_{E}{ }^{\mathrm{grB}}$ if this term is included. We do not choose gyro-reduced Bohm scaling because of the uncertainty in the dependence of $\tau_{E}$ on the ion mass and because recent data ${ }^{10}$ from the ATF torsatron indicate an improvement over gyro-reduced Bohm scaling, $\tau_{E} \propto \tau_{\mathrm{grB}} \times\langle\beta\rangle^{0.3}\left(1 / \mathrm{N}^{*}\right)^{0.2}$, where $\mathrm{V}^{*} \propto n / T^{2}$ is the collisionality and $T$ is the plasma temperature. This modification would increase the value of $\tau_{E}$ for typical reactor parameters by a factor of $\sim 2$.

Coincidentally, the Lackner-Gottardi and LHD scalings also give nearly the same value of $\tau_{E}$ for typical reactor cases, even though they have different functional dependences on the reactor parameters.

We therefore select for our study the Lackner-Gottardi scaling with a confinement improvement factor $\mathrm{H}^{\prime}$ similar to the $\mathrm{H}$-mode confinement improvement factor for tokamaks. The improvement with the square root of the ion mass $A_{i}$ used in tokamak scaling is not assumed in our study, and the rotational transform $\ell$ is evaluated at a normalized radius $p=r / a_{p}=2 / 3$, rather than at the plasma edge; reversing either of these assumptions would improve the confinement time by a factor of 1.2-1.3.

The relatively large helical ripple in torsatrons, combined with symmetry-breaking toroidal effects, can lead to a near-perpendicular loss region for energetic particles. Alpha particles that are born in this region are rapidly lost, as are alpha particles that pitch-angle scatter into it as they slow down on (and transfer energy to) the background plasma. Modification of the magnetic configuration properties can significantly reduce the extent of this loss region, even to the point where the alpha-particle loss becomes negligible. 5 However, to be conservative, we assume that all helically trapped alpha particles are lost and calculate the energy lost by pitch-angle scattering into the loss region during the slowing-down process. The combined loss can reduce the effective alpha-particle heating by up to $\sim 40 \%$. Most of the alpha particles are not born in the loss region and transfer their energy to the background plasma as they slow down from their $3.5-\mathrm{MeV}$ birth energy to an energy $E \approx 30 T_{\mathrm{e}}-0.3 \mathrm{MeV}$, below which they rapidly scatter into the loss region. The eventual loss of alpha particles by pitch-angle scattering into a near-perpendicular loss region has a compensating side effect. This loss prevents accumulation of helium ash in the plasma and the attendant dilution of the fuel ions, thereby both increasing the fusion reaction rate and decreasing the bremsstrahlung radiation loss.

The radiation losses calculated include both bremsstrahlung and synchrotron radiation. Impurities are modeled by $1 \%$ oxygen (plus $8 \%$ helium if no alpha-particle loss region exists), giving $n_{\mathrm{DT}} / n_{\mathrm{e}}=0.92$ and $Z_{\mathrm{eff}}=1.56\left(n_{\mathrm{DT}} / n_{\mathrm{e}}=0.85\right.$ and $Z_{\mathrm{eff}}=1.7$ if no loss region exists). Synchrotron radiation losses are computed using a wall reflectivity 
of 50\%, as in ARIES-I. The total radiation and alpha-particle heating power are found by numerically integrating over the plasma volume using the density and temperature profiles assumed in the ARIES-I studies: $n=\left(n_{0}-n_{\mathrm{S}}\right)\left(1-\rho^{2}\right)^{\mathrm{c}} n+n_{\mathrm{S}}$ and $T_{\mathrm{e}}=T_{\mathrm{i}}=$ $T_{0}\left(1-\rho^{2}\right)^{\alpha_{T}}$, where $\alpha_{n}=1.0, n_{\mathrm{s}} / n_{0}=0.538$, and $\alpha_{T}=1.1$.

\section{SELECTION OF A REFERENCE CASE}

The main differences between stellarator and tokamak reactors arise from the coil geometry and the confinement assumptions.

\section{IV.A. Choice of a Reference Stellarator Configuration}

A specific winding geometry must be used when applying engineering and reactorcomponent constraints in stellarator reactor optimization: the shape of the winding cross section, the maximum field on the superconductor, the distance between coils or windings for blanket segments, etc.

The reference ste iastor configuration chosen to illustrate stellarator reactor optimization is a Compac Fesatron 33 with six toroidal field periods (CT6). The helical winding geometry and the last closed flux surface for this configuration are shown in Fig. 2. The two helical windings are characterized by a helical winding aspect ratio $A_{\mathrm{c}} \equiv$ $R_{0} / a_{\mathrm{c}}=2.5$, where $a_{\mathrm{c}}$ is the minor radius of the helical winding, and $I_{\mathrm{HF}} / B_{0} R_{0}=$ $0.83 \mathrm{~m} / \mathrm{H}$, with $I_{\mathrm{HF}}$ the current in the helical windings. The two vertical field (VF) coils (not shown) are characterized by $R / R_{0}=1.5, z / R_{0}= \pm 0.5$, and $I_{\mathrm{VF}} / B_{0} R_{0}=0.275 \mathrm{~m} / \mathrm{H}$, where $R$ and $z$ are the major radius and vertical position of the VF coils and IVF is the current in the VF coils. The relatively open coil geometry allows access between the helical windings for blanket removal and maintenance without disassembly of the reactor core. The vacuum magnetic surfaces were calculated using the optimized helical winding trajectory and VF coil locations. The outermost (last closed) magnetic surface is characterized by $A_{\mathrm{p}}=3.87$ and $\mathrm{K}=2.1$.

Figure 2 shows that, although the space between the plasma edge and the helical winding on the outboard half of the torus is more than adequate, the space on the inboard half of the torus is more critical. The minimum distance $\Delta$ between the edge of the plasma (the last closed flux surface) and the centerline of the helical winding or modular coil determines the minimum size for a stellarator reactor because the ratio $A_{\Delta} \equiv R_{0} / \Delta$ is a constant for a given stellarator coil configuration $\left(A_{\Delta}=6.64\right.$ for CT6). This is not a constraint for tokamaks because the position of the plasma edge and the edge configuration properties, other than the TF ripple, do not depend on the proximity of the TF coils. The need to reduce the TF ripple and allow adequate access for maintenance requires the outer leg of the TF coils in tokamaks to be relatively far from the plasma edge (e.g., $R_{\text {outer }} / R_{0}$ is 1.58 for ARIES-I, versus 1.4 for CT6). In contrast, the helical windings must be relatively close to the plasma edge in torsatrons to produce the edge shear needed for magnetohydrodynamic (MHD) stabilization [e.g., $a_{\mathrm{c}} / a_{\mathrm{p}}$ is low $(=1.55)$ for CT6, versus 2.32 for ARIES-I, partly because the plasma bulges out between the helical windings in 

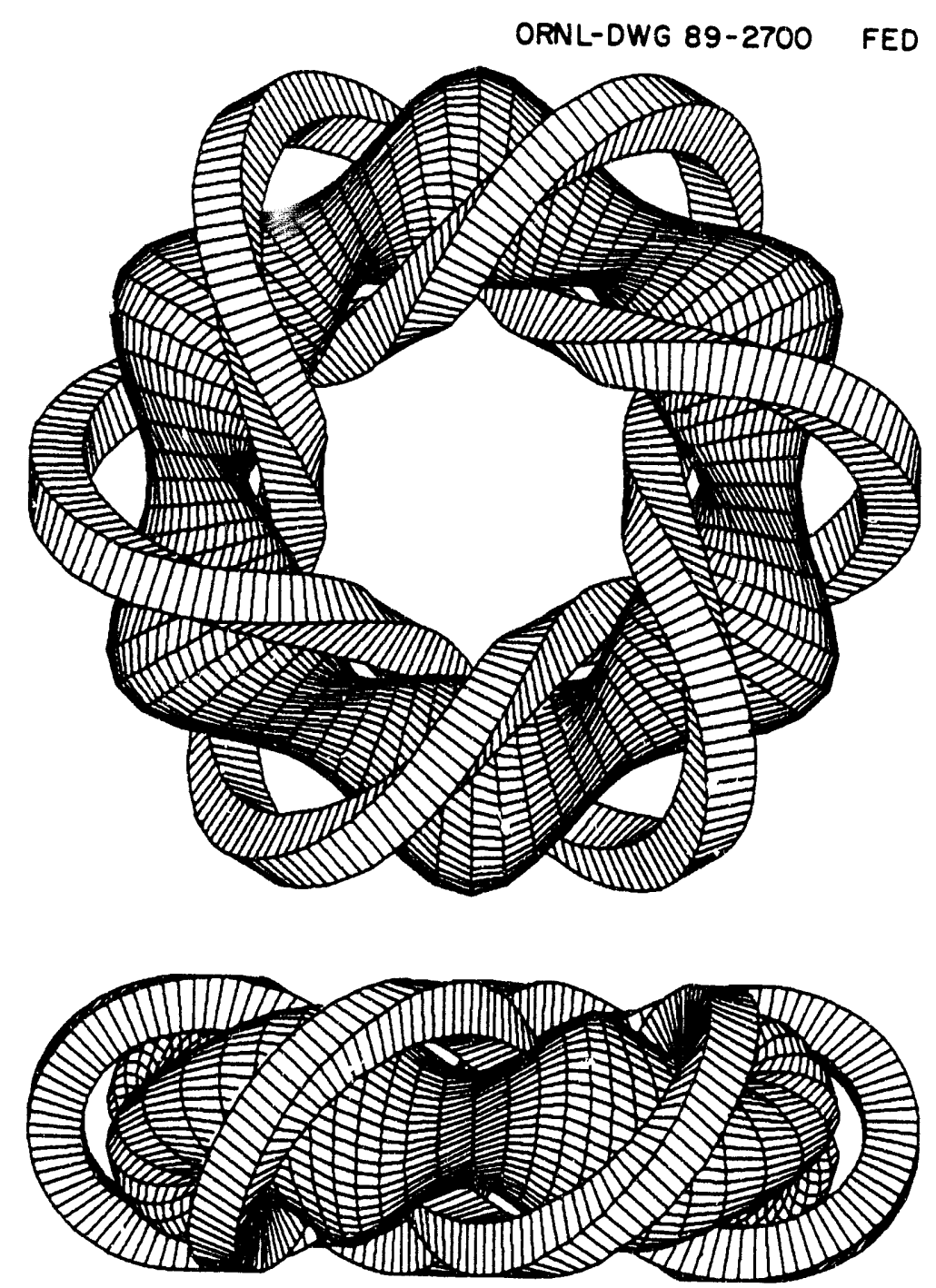

Fig. 2. Top and side views of the helical windings and last closed flux surface for Compact Torsatron CT6 with six toroidal field periods.

torsatrons]. The nonplanar TF coils must also be relatively close to the plasma edge in modular stellarators to permit practical coil designs. For both types of stellarator coils, an optimized magnetic configuration requires precise shaping of the external current paths; the resulting higher-order field components decay rapidly away from the windings, necessitating closeness to the plasma to avoid excessively large currents.

A certain distance $d$ is required for the plasma-wall separation, the first wall, the tritium breeding blanket, the neutron shielding, the coil dewar, the structural case facing the plasma, and the half-thickness of the coil winding pack. The minimum value possible for $R_{0}$ is thus $A_{\Delta} d$ because $d$ must be $\leq \Delta$. Minimizing $d$ (in particular, the radial depth of the winding pack and the blanket thickness under the inboard half of the helical winding) and $A_{\Delta}$ is important in reducing the cost of torsatron reactors because the cost increases with $R_{0}$. The smaller value of $A_{\Delta}$ obtained in Compact Torsatrons ${ }^{33}$ allows this type of 
reactor ${ }^{18}$ to be a factor of $\sim 2.5$ smaller than modular stellarator reactors; typically $R_{0}$ 6-9 m versus $R_{0}-20-25 \mathrm{~m}$.

Although a continuous helical winding is used in most of the examples in this study, these coil configurations can be modularized to have one (or two) coils per toroidal field period (e.g., the "symmotron" configuration, ${ }^{34}$ shown in Fig. 3a) or five to ten coils per field period (the "Garching" modularization scheme, ${ }^{35}$ shown in Fig. 3b). The effect of both types of modularizations on the COE is discussed in Sec. VI.F.

\section{IV.B. Choice of Reference Assumptions}

The two main stellarator-specific assumptions are the confin ent improvement factor $\mathrm{H}^{\prime}$ and the thickness $b_{\mathrm{i}}$ of the blanket under the inboard half of the helical winding. We choose $\mathrm{H}^{\prime}=2.5$ as representing a reasonable target for stellarator confinement improvement. Similar or better confinement improvement factors have been obtained in tokamaks. ARIES-I* also requires $\mathrm{H}^{\prime}=2.5$. There is already some evidence for improved confinement operation in stellarators. Wendel i VII-AS (Ref. 36) and CHS (Ref. 37) discharges show H-mode characteristics and unit improvement in confinement similar to the early H-mode results in tokamaks. An improvement over gyro-reduced Bohm scaling is seen in the ATF torsatron. Possible confinement improvement techniques include control of the edge electric field, operation in the second stability regime, 38 and field shaping to reduce the effective field ripple.
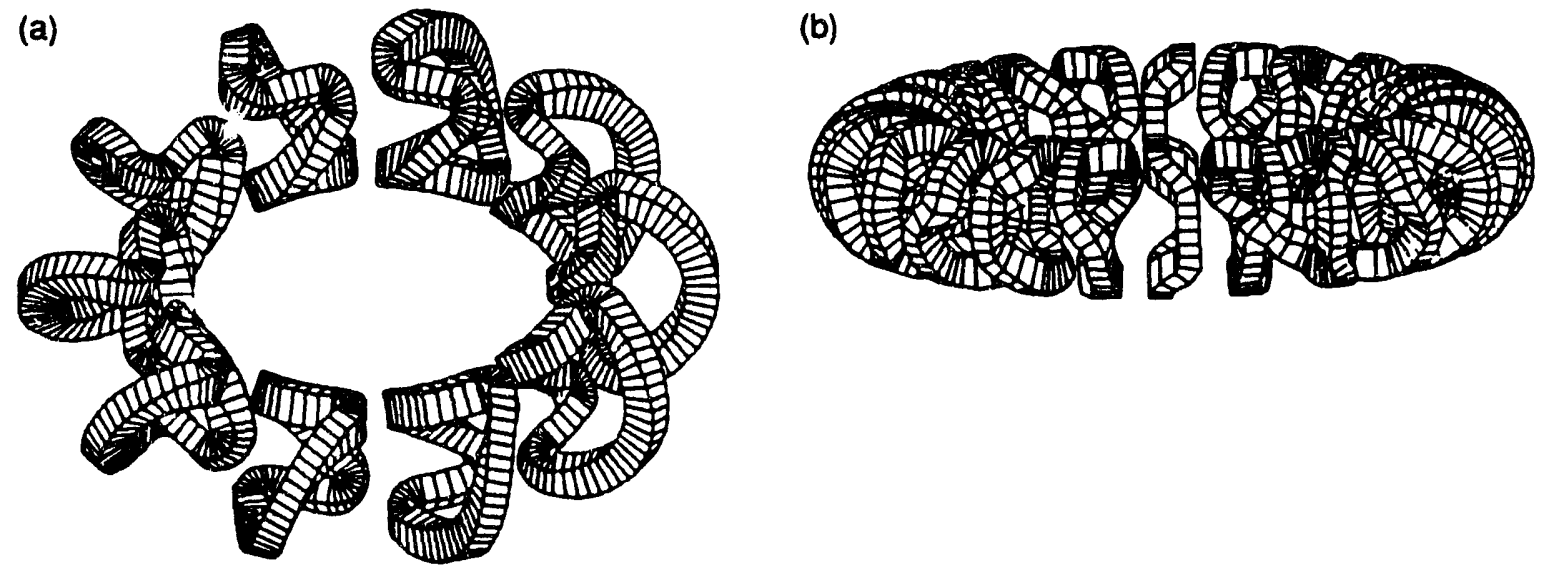

Fig. 3. Torsatrons can be modularized with (a) one coil per field period, the "symmotron," or (b) several nonplanar coils per sield period (typically five to ten, but three in this illustration). 
We choose $b_{\mathrm{i}}=0$ because the inboard half of the helical winding typically covers $<20 \%$ of the area available for the tritium breeding blanket. The decrease in the global tritium breeding ratio can be compensated for by increasing the local tritium breeding ratio by a corresponding amount (higher beryllium fraction). However, for costing purposes we assume $b_{\mathrm{i}}=0.67 \mathrm{~m}$ in calculating the total blanket mass. The transverse elongation $k$ of the helical winding is chosen to be 3 (versus 2.6 for ARIES-I) as a compromise (higher values of $k$ yield a smaller coil depth that leads to a smaller $R_{0}$ and a lower COE, while lower values yield more room for blankets between the helical windings on the inboard side). The LSA credits are the same as those assumed for ARIES-I $($ LSA $=2)$.

\section{COMPARISON OF THE REFERENCE CT6 CASE WITH ARIES-I*}

The main plasma parameters for the CT6 reference case are compared with those for ARIES-I* in Table III. The CT6 reference case has a slightly smaller major radius and $20 \%$ smaller plasma volume. The density-averaged temperature $\langle T\rangle$ is only one-third that in ARIES-I*; it is not constrained to a high value by the need for efficient current drive. The volume-averaged density $\langle n\rangle$ is correspondingly higher. The resulting beta is 2.5 times higher for CT6; the beta for ARIES-I is constrained to a low value by the modest plasma current (9.5 MA) and the high central magnetic field $(10.6 \mathrm{~T})$ through the tokamak Troyon beta limit. A major difference is the large loss of alpha-particle power

TABLE III

Main Plasma Parameters for Reference CT6 Torsatron and ARIES-I* Reactors

\begin{tabular}{lll}
\hline & CT6 & ARIES-I* \\
\hline Major radius $R_{0}(\mathrm{~m})$ & 6.57 & 6.75 \\
Average plasma radius $a_{\mathrm{p}}(\mathrm{m})$ & 1.74 & 1.95 \\
Plasma ellipticity $\mathrm{k}$ & 2.1 & 1.8 \\
Plasma volume $\left(\mathrm{m}^{3}\right)$ & 394 & 489 \\
Edge safety factor $q$ & 1.05 & 4.5 \\
Electron density $\langle n\rangle\left(10^{20} \mathrm{~m}^{-3}\right)$ & 3.18 & 1.43 \\
Plasma temperature $\langle T\rangle(\mathrm{keV})$ & 6.84 & 20 \\
Central ion temperature $(\mathrm{keV})$ & 13.0 & 39.0 \\
Volume-average toroidal beta $(\%)$ & 4.7 & 1.9 \\
Fraction of alpha-particle power lost & 0.42 & 0 \\
Fraction of plasma power radiated & 0.47 & 0.47 \\
Energy confinement time $\tau_{E}(\mathrm{~s})$ & 3.61 & 2.51 \\
Plasma Q value & $\infty$ & 5.27 \\
\hline
\end{tabular}


in CT6 that must be compensated for by an increase of $44 \%$ in the energy confinement time.

Table IV gives the main device parameters for CT6 and ARIES-I*. The field on axis for CT6 is $56 \%$ of that in ARIES-I*, the maximum field on the helical winding is $80 \%$ of that on the TF coil in ARIES-I*, and the total stored magnetic energy is $44 \%$ of that in ARIES-I*. The fusion power, thermal power, and gross electric power are more for ARIES-I* because of the current drive requirements. The total mass of the CT6 fusion power core is 4,747 tonnes, versus 10,067 tonnes for ARIES-I*, resulting in a mass utilization efficiency 2.1 times that of ARIES-I*, a $22 \%$ lower unit direct cost, and an $18 \%$ lower COE. The neutron wall loading is the same for both because the smaller CT6 wall area offsets the lower neutron production.

There are two main reasons for the lowc:" costs for CT6: the absence of current drive and the smaller magnet mass. Because no power is needed for current drive in CT6, the recirculating power fraction is only $9 \%$ (versus $19 \%$ for ARIES-I*) and the cost of the supplemental heating system (only needed for plasma startup) is much lower, as shown in Table V. However, the cost of the power supply for switching and storage is assumed to be the same. The mass of the CT6 helical winding is a factor of 4.5 lower than the mass of the ARIES-I* TF coils because the magnet perimeter is smaller (the CT6 winding is closer to the plasma) and the winding cross section is much smaller (fewer total ampere-turns and higher average current density because of the lower magnetic field). The masses of the accompanying coil support structure and the VF coils are also much smaller for CT6. The primary reason for the lower current density in ARIES-I is the larger amount of internal structure needed for the hoop force, corresponding to the last term in the denominator in Eq. (3); $B_{0}, R_{0}$, and $R_{\text {outer }} / R_{\text {inner }}$ are all larger for ARIES-I.

The total reactor equipment cost (whose elements are shown in Table V) is $\$ 841$ million (versus $\$ 1289$ million for ARIES-I*), and the total reactor plant equipment cost is $\$ 1163$ million (versus $\$ 1628$ million for ARIES-I*). The geometry-dependent fusion power core components (blanket and first wall, divertor, shields, magnets, vacuum vessel, and primary structure) are only $42 \%$ of the $\$ 1819$ million total direct cost for CT6 and $49 \%$ of the $\$ 2318$ million total direct cost for ARIES-I*; components that deperid on the thermal and electrical power make up the remainder. The total capital cost $\$ \$ 3509$ million for CT6 and $\$ 4473$ million for ARIES-I*) is almost twice the total direct cost for both because of financial charges that are proportional to the total direct cost and depend on the LSA credits assumed. The COE for the CT6 reference case is $18 \%$ less than that for ARIES-I* because the annual capital cost charge, which is $76 \%$ of the total COE, is proportional to the total capital cost; the total direct cost and the total capital cost for CT6 are $78 \%$ of those for ARIES-I*. 
TABLE IV

Main Device Parameters for Reference CT6 Torsatron and ARIES-I* Reactors

\begin{tabular}{|c|c|c|}
\hline & CT6 & ARIES-I* \\
\hline Toroidal field on axis ( $\mathrm{T}$ ) & 6.0 & 10.6 \\
\hline Maximum field on coils $B_{\max }(\mathrm{T})$ & 16.0 & 19.9 \\
\hline HF/TF coil current (MA·turns) & $32.8(\times 6)$ & $22.3(\times 16)$ \\
\hline $\mathrm{HF} / \mathrm{TF}$ coil current density $j\left(\mathrm{MA} / \mathrm{m}^{2}\right)$ & 55 & 31 \\
\hline Inboard clearance between coils (m) & 0.9 & 0 \\
\hline Outboard clearance between coils (m) & 4.2 & 2.6 \\
\hline VF coil current (MA.turns) & $10.8(\times 2)$ & $31.1(\times 2)$ \\
\hline Current-drive power (MW) & 0 & 89.3 \\
\hline Fusion power (MW) & 1763 & 1908 \\
\hline Neutron wall loading $\left(\mathrm{MW} / \mathrm{m}^{2}\right)$ & 2.8 & 2.7 \\
\hline Thermal power (MW) & 2243 & 2519 \\
\hline Gross electric power $[\mathrm{MW}(\mathrm{e})]$ & 1099 & 1234 \\
\hline Recirculating power percentage (\%) & 9 & 19 \\
\hline Net electric output [MW(e)] & 1000 & 1000 \\
\hline Mass power density [kW(e)/tonne] & 211 & 99.3 \\
\hline Unit direct cost $[\$ / k W(e)]^{(a)}$ & 1819 & 2318 \\
\hline Cost of electricity [mill/ $/ \mathrm{kW}(\mathrm{e}) \mathrm{h}]^{(\mathrm{a})}$ & 67.0 & 81.4 \\
\hline
\end{tabular}

(a)In constant 1990 oliars.

TABLE $\mathrm{V}$

Costs of Reactor Equipment for Reference CT6 Torsatron and ARIES-I* Reactors

\begin{tabular}{lcc}
\hline & \multicolumn{2}{c}{ Costs(a) } \\
\cline { 2 - 3 } Item & CT6 & ARIES-I* \\
\hline Blanket and first wall & 451.8 & 469.5 \\
Shields & 215.1 & 214.6 \\
Magnets & 73.2 & 365.4 \\
Supplemental heating systems & 22.0 & 98.2 \\
Primary structure and support & 9.1 & 58.6 \\
Reactor vacuum systems & 11.6 & 20.8 \\
Power supply, switching, storage & 52.5 & 52.5 \\
Impurity control & 5.6 & 5.4 \\
ECH breakdown system & 0 & 4.1 \\
Total reactor equipment & $\mathbf{8 4 0 . 8}$ & $\mathbf{1 2 8 9 . 1}$ \\
\hline
\end{tabular}

(a) In constant 1990 dullars. 


\section{SENSITIVITY TO ASSUMPTIONS}

\section{VI.A. Confinement and Blanket Assumptions}

Figures 4 and 5 show the variation of the plasma and device parameters with $\mathrm{H}^{\prime}$. Improved energy confinement is reflected most strongly in a factor of 4 increase in $\langle\beta\rangle$, from $1.5 \%$ to $6 \%$, and a factor of 2.3 decrease in the plasma volume $V$ (which has the same variation as $\tau_{E}$ ), from $824 \mathrm{~m}^{3}$ to $356 \mathrm{~m}^{3}$, as $\mathrm{H}^{\prime}$ increases from 1.65 to 3 . For $\mathrm{H}^{\prime}<$ 2.75 (i.e., when $\langle\beta\rangle$ is less than the prescribed limit of $6 \%$ and $\langle T\rangle$ is essentially constant), $\langle n\rangle \propto \tau_{E} 1 / 2$ because the fixed fusion power $P_{\text {fus }} \propto\langle n\rangle^{2} f(\langle T\rangle) V$ and $V \propto \tau_{E}$. For $\mathrm{H}^{\prime} \geq 2.75$, $\tau_{E}$ (hence $V$ ) and $B_{0}$ are approximately constant, $\langle n\rangle \propto 1 /\langle T\rangle$ for $\langle\beta\rangle$ that is fixed at $6 \%$, and $\langle T\rangle$ increases to keep $P_{\text {fus }}$ constant.

Figure 5 shows a large decrease in $B_{0}$ and a smaller decrease in $R_{0}$ as $\mathrm{H}^{\prime}$ is increased. The decrease in $R_{0}\left[=A_{\Delta}\left(c w+b_{\mathrm{i}}+s o\right)\right.$ ] is due to the decrease in $c w$, which is approximately the same for $b_{\mathrm{i}}=0$ and $0.335 \mathrm{~m}$; the scrape-off distance so is assumed to be constant at $0.1 \mathrm{~m}$. The mass of the fusion power core decreases continuously from 11,910 tonnes at $\mathrm{H}^{\prime}=1.65$ to 4,210 tonnes at $\mathrm{H}^{\prime}=3$. The rapid reduction in the mass with increasing $\mathrm{H}^{\prime}$ is due to smaller masses for the coil systems and for the blankets and shields $\left(\propto R_{0}{ }^{2}\right.$ ). Figure 6 shows the relative contributions of the component costs to the reactor equipment cost as $\mathrm{H}^{\prime}$ is varied from 1.65 to 3 . The helical and VF coil masses decrease with increasing $\mathrm{H}^{\prime}$ because of both the decreasing coil lengths $\left(\propto R_{0}\right)$ and the decreasing coil cross sections [area $\propto B_{0} R_{0} / j$, where both $B_{0}$ and $R_{0}$ decrease with

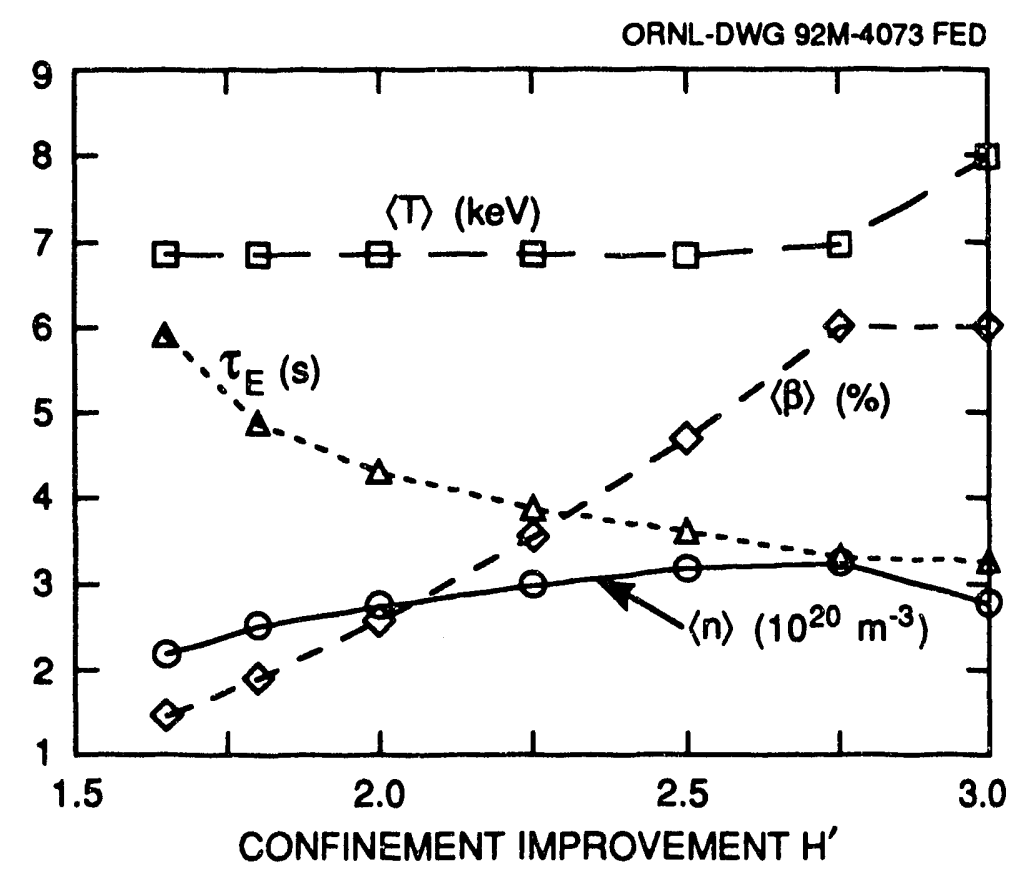

Fig. 4. Dependence of the reactor plasma parameters on the confinement improvement factor $\mathrm{H}^{\prime}$ for $b_{\mathrm{i}}=0$. 


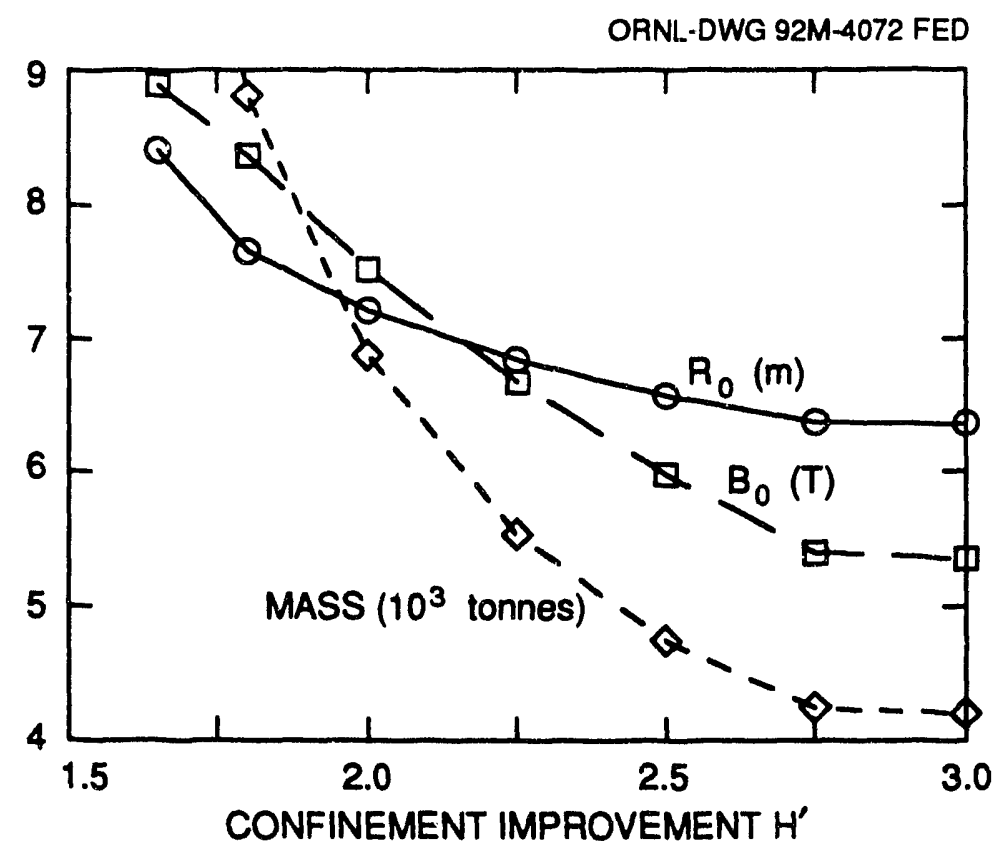

Fig. 5. Dependence of the reactor device parameters on the confinement improvement factor $\mathrm{H}^{\prime}$ for $b_{\mathrm{i}}=0$.

increasing $\mathrm{H}^{\prime}$ and $j$ increases (from $24 \mathrm{MA} / \mathrm{m}^{2}$ at $\mathrm{H}^{\prime}=1.65$ to $67 \mathrm{MA} / \mathrm{m}^{2}$ at $\mathrm{H}^{\prime}=3$ )]. As seen in Table $\mathrm{V}$ and Fig. 6 , the costs of the blankets and shields are approximately the same for the reference $\mathrm{CT} 6$ case $\left(\mathrm{H}^{\prime}=2.5\right)$ and ARIES-I*. The difference is in the costs of the magnets and the other systems.

The COE is shown versus $\mathrm{H}^{\prime}$ in Fig. 7 for two different values of $b_{\mathrm{i}}$. Adding a 0.335-m-thick blanket, half the thickness of the blanket used in ARIES-I but thicker than the beryllium-rich blankets used in earlier reactor studies, ${ }^{18}$ increases the COE to a level in at is closer to the ARIES-I* value. The COE is less than that for ARIES-I* for $\mathrm{H}^{\prime}>$ $1.75\left(b_{\mathrm{i}}=0\right)$ and $\mathrm{H}^{\prime}>2.3\left(b_{\mathrm{i}}=0.335 \mathrm{~m}\right)$. Two CT6 examples, summarized in Table VI, are used for comparisons with the CT6 reference case (indicated by the solid circle in Fig. 7): (1) a case with the thicker blanket under the inboard half of the HF windings $\left(b_{\mathrm{i}}=0.335 \mathrm{~m}\right)$ and the same confinement improvement as the reference case $\left(\mathrm{H}^{\prime}=2.5\right)$, indicated by the square containing a " + " in Fig. 7; and (2) a case with the same blanket thickness under the inboard half of the HF windings as the reference case $\left(b_{\mathrm{i}}=0\right)$ and a smaller confinement improvement $\left(\mathrm{H}^{\prime}=2\right)$, indicated by the symbol " $\Theta$ " in Fig. 7. 


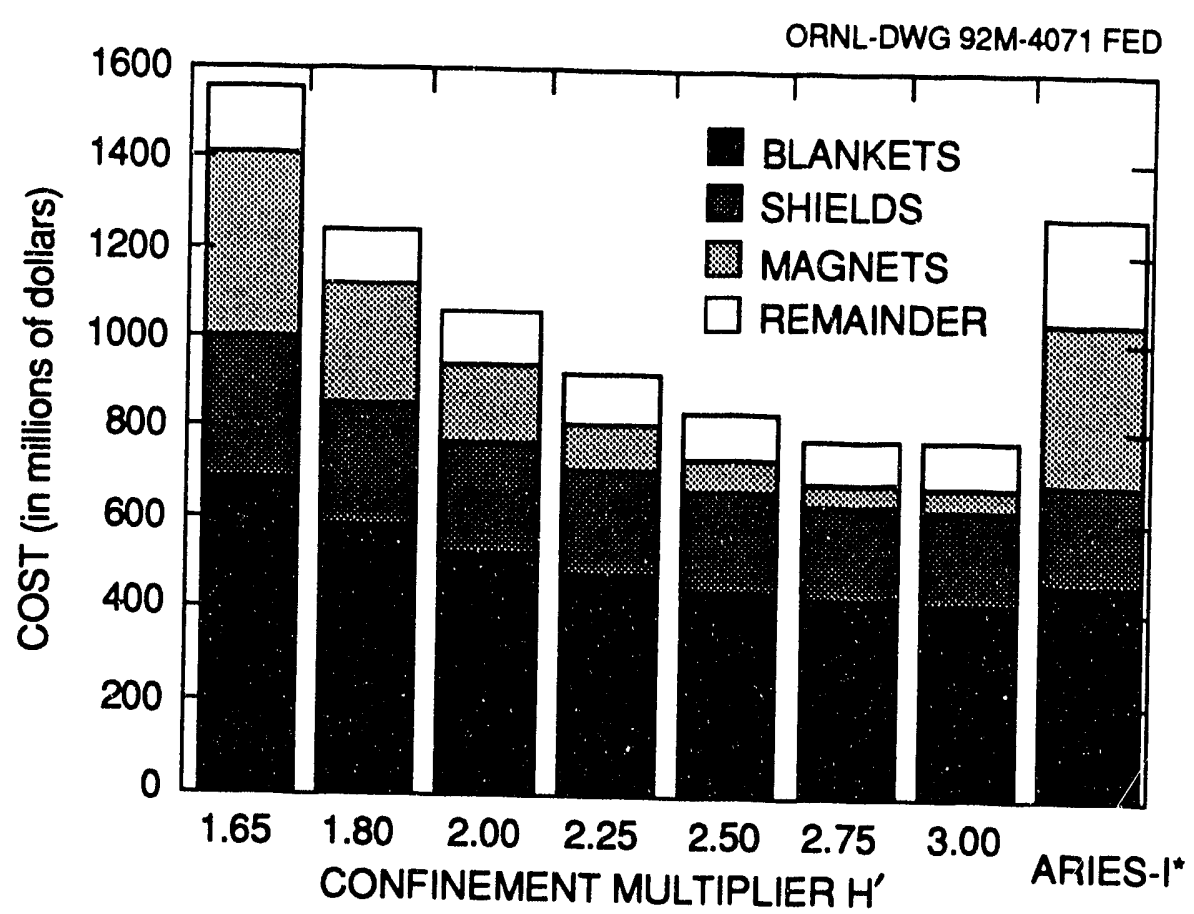

Fig. 6. Dependence of the reactor component costs on the confinement improvement factor $\mathrm{H}^{\prime}$ for $b_{\mathrm{i}}=0$.

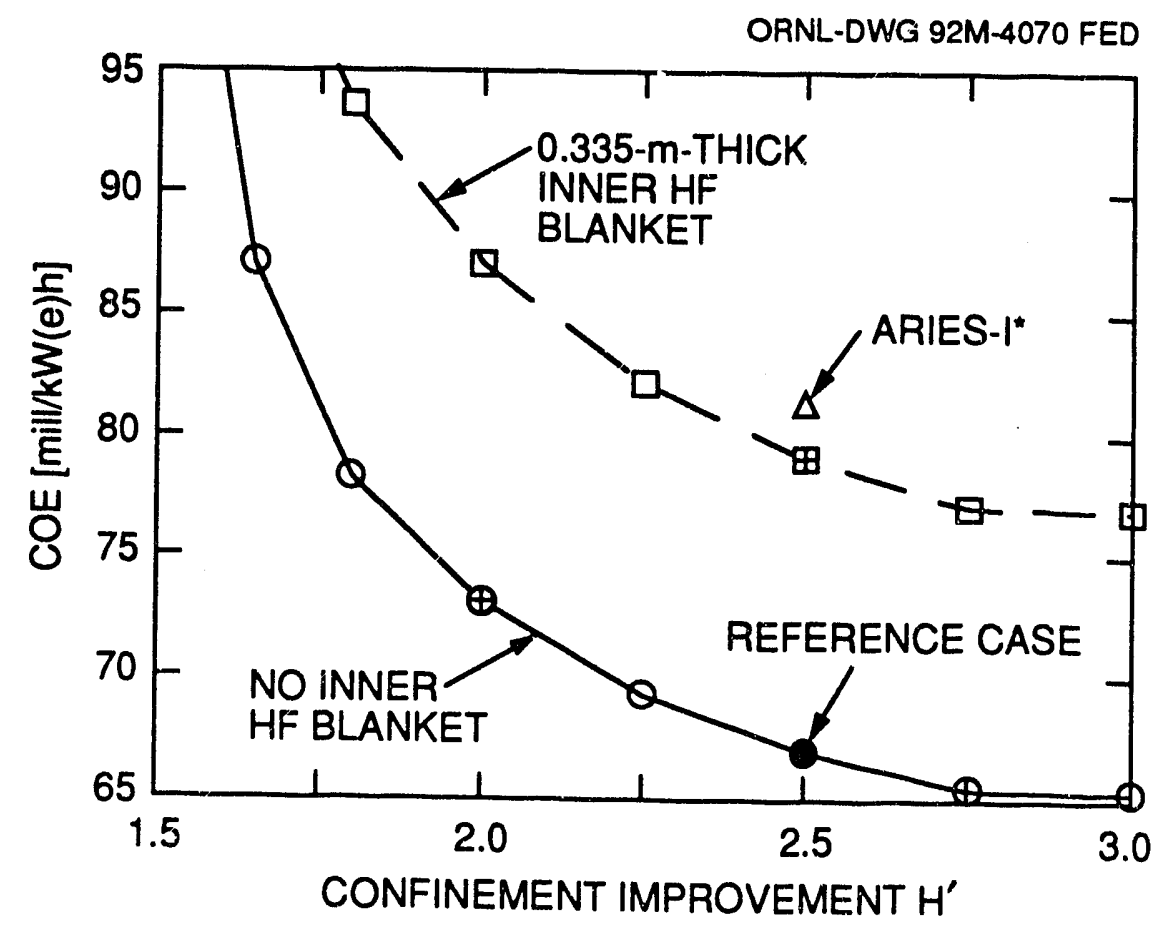

Fig. 7. Variation of the COE with the confinement improvement factor $\mathrm{H}^{\prime}$ for two different blanket thicknesses under the inboard half of the helical windings. 
TABLE VI

Main Plasma and Device Parameters for Different CT6 Torsatron Reactors

\begin{tabular}{|c|c|c|c|}
\hline & $\begin{array}{c}b_{\mathrm{i}}=0 \\
\mathrm{H}^{\prime}=2.5\end{array}$ & $\begin{array}{c}b_{\mathrm{i}}=0.335 \mathrm{~m} \\
\mathrm{H}^{\prime}=2.5\end{array}$ & $\begin{array}{c}b_{\mathrm{i}}=0 \\
\mathrm{H}^{\prime}=2.0\end{array}$ \\
\hline Major radius $R_{0}(\mathrm{~m})$ & 6.57 & 8.75 & 7.22 \\
\hline Average plasma radiu: $a_{\mathrm{p}}(\mathrm{m})$ & 1.74 & 2.32 & 1.91 \\
\hline Plasma volume $\left(\mathrm{m}^{3}\right)$ & 394 & 928 & 521 \\
\hline Electron density $\langle n\rangle\left(10^{20} \mathrm{~m}^{-3}\right)$ & 3.18 & 2.07 & 2.75 \\
\hline Plasma temperature $\langle T\rangle(\mathrm{keV})$ & 6.84 & 6.83 & 6.86 \\
\hline Central ion temperature (keV) & 13.0 & 13.0 & 13.0 \\
\hline Volume-averaged toroidal beta (\%) & 4.7 & 4.7 & 2.6 \\
\hline Fraction of alpha-particle power lost & 0.42 & 0.42 & 0.42 \\
\hline Fraction of plasma power radiated & 0.47 & 0.47 & 0.49 \\
\hline Energy confinement time $\tau_{E}(s)$ & 3.61 & 5.55 & 4.31 \\
\hline Toroidal field on axis $(\mathrm{T})$ & 6.0 & 4.82 & 7.52 \\
\hline Maximum field on coils $B_{\max }(\mathrm{T})$ & 16.0 & 16.0 & 16.0 \\
\hline HF/TF coil current (MA·turns) & $32.8(\times 6)$ & $35.2(\times 6)$ & $45.2(\times 6)$ \\
\hline HF/TF coil current density $j\left(\mathrm{MA} / \mathrm{m}^{2}\right)$ & 55 & 56 & 36 \\
\hline Inboard clearance between coils (m) & 0.9 & 1.8 & 0.5 \\
\hline Outboard clearance between coils (m) & 4.2 & 6.3 & 4.1 \\
\hline VF coil current (MA'turns) & $10.8(\times 2)$ & $11.6(\times 2)$ & $14.9(\times 2)$ \\
\hline Neutron wall loading $\left(\mathrm{MW} / \mathrm{m}^{2}\right)$ & 2.8 & 1.6 & 2.3 \\
\hline Mass power density $[\mathrm{kW}(\mathrm{e}) /$ tonne $]$ & 211 & 137 & 145 \\
\hline Unit direct cost $[\$ / k W(e)]^{(a)}$ & 1819 & 2268 & 2041 \\
\hline Cost of electricity [mill/kW(e)h] $]^{(a)}$ & 67.0 & 79.2 & 73.1 \\
\hline
\end{tabular}

(a) In constant $199 \mathrm{C}$ dollars.

\section{VI.B. Coil Assumptions}

A nominal set of coil parameters was chosen for the base reference case. The most critical parameters $\left(j_{\max }, k\right.$, and $B_{\max }$ ) were varied over representative ranges to test the sensitivity of the reactor parameters to these choices. The relatively high current density for the reference CT6 case (1.8 times that for the high-field ARIES-I) has only a modest effect on the COE. Decreasing $j_{\max }$ by a factor of two only increases the COE by $4.6 \%$, and arbitrarily fixing $j$ at $30 \mathrm{MA} / \mathrm{m}^{2}$ only increases the COE by $7.3 \%$.

Larger changes in the COE occur as $k$ is varied, as shown in Fig. 8. For $k=1$ (a square coil cross section), the $\mathrm{COE}$ is $15 \%$ larger than for $k=3$ and the area under the inboard half of the helical winding decreases to $13 \%$ of the area available for the blanket (versus $18 \%$ for the reference CT6 case). A corresponding variation for the COE is seen in Fig. 8 for the $b_{\mathrm{i}}=0.335-\mathrm{m}$ cases. Figure 8 indicates that competitive reactors are 


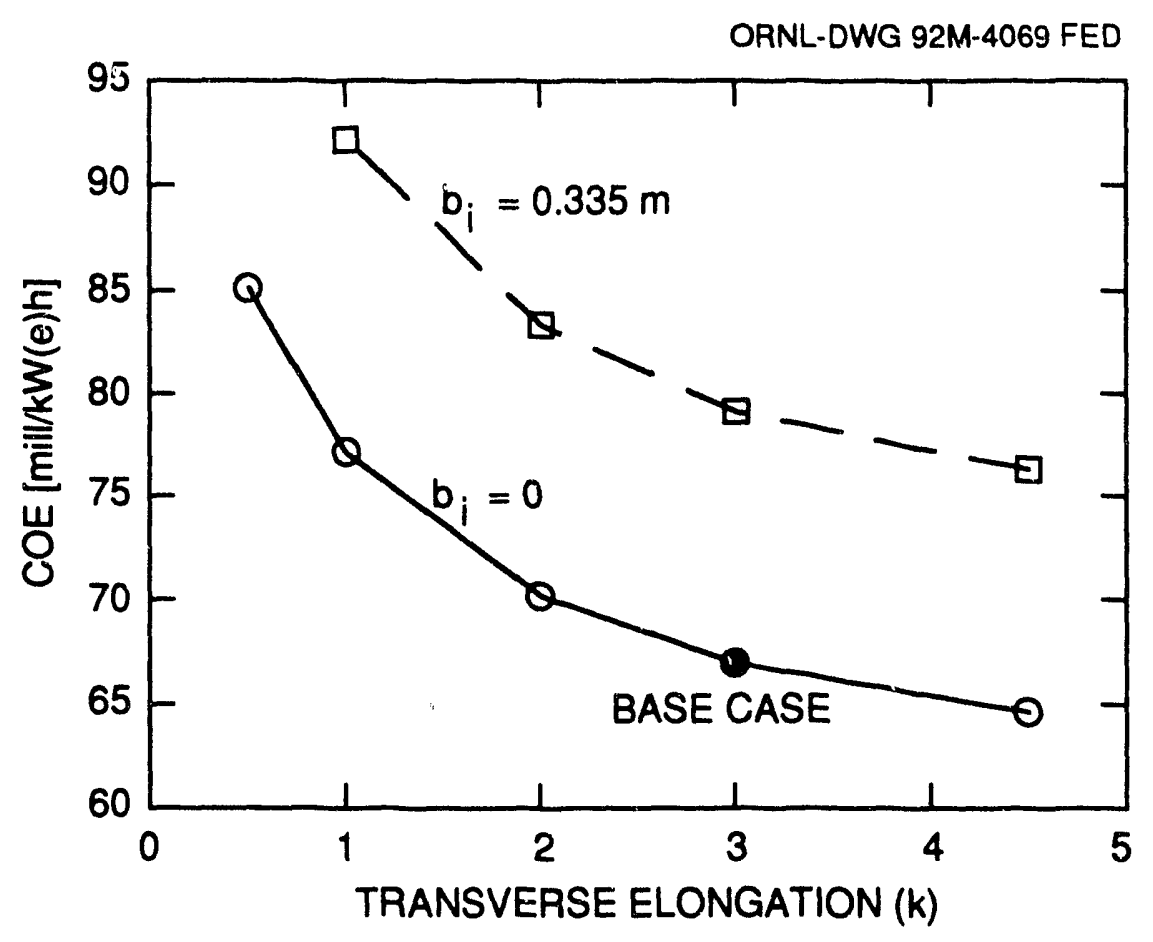

Fig. 8. Variation of reactor parameters with the transverse elongation of the helical winding pack.

possible even if $k$ must be reduced significantly below 3 to allow space for additional shielding or blankets between coils on the inboard side.

The reference CT6 case had $B_{\max }=16 \mathrm{~T}$. Lower values of $B_{\max }$ are possible at somewhat increased values of the $\mathrm{COE}$, as shown in Fig. 9. The case with $B_{\max }=12 \mathrm{~T}$, $60 \%$ of that for ARIES-I*, and a COE of $72.8 \mathrm{mill} / \mathrm{kW}(\mathrm{e}) \mathrm{h}, 11 \%$ less than that for ARIES-I*, may be more attractive than the reference CT6 case with higher $B_{\max }(16 \mathrm{~T})$ and lower COE [67 mill/kW(e)h]. The COE decreases with increasing $B_{\max }$ (and $B_{0}$ ) because $R_{0}$ decreases from $8.3 \mathrm{~m}$ at $B_{\max }=9 \mathrm{~T}$ to $6.4 \mathrm{~m}$ at $B_{\max }=17.3 \mathrm{~T}$. A corresponding variation for the COE is seen in Fig. 9 for the $b_{\mathrm{i}}=0.335-\mathrm{m}$ cases.

The reactor costs are relatively insensitive to additional costs related to fabrication of the more complex stellarator coils; increasing the cost of the helical and VF coils by a factor 'of 2 increases the COE by only $3 \%$. The reactor costs are more sensitive to additional. costs associated with the blankets and shields; increasing the costs of the blankets and shields by a factor of 1.5 , in addition to the factor of 2 increase in the cost of the superconducting coils, increases the COE by $22 \%$. However, none of the variations considered (except $B_{\max }<10 \mathrm{~T}$ ) leads to a COE as high as that for ARIES-I* (22\% higher than the reference CT6 case). 


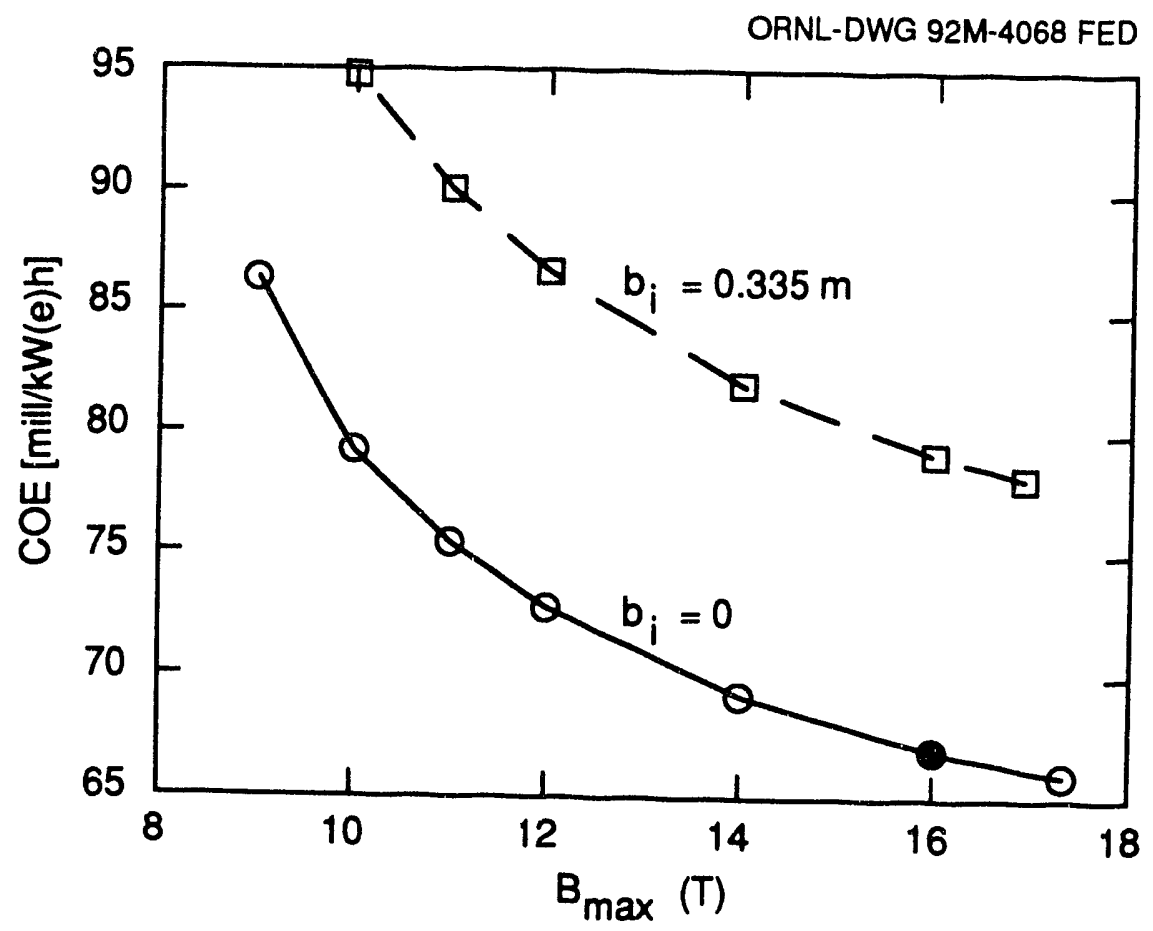

Fig. 9. Variation of reactor parameters with the maximum field on the superconducting winding pack.

\section{VI.C. Other Parameter Assumptions}

A nominal set of physics parameters was chosen for the base reference case. These parameters were then varied over representative ranges to test the sensitivity of the reactor parameters to these choices: the fraction of helically and toroidally trapped alpha particles lost from 0 to $100 \%$; the fraction of oxygen impurities from $0.5 \%$ to $1.5 \%$; the wall reflectivity from $50 \%$ to $90 \%$; and the shapes of the density and temperature profiles. Several of these variations (e.g., more peaked density and temperature profiles, higher wall reflectivity, lower oxygen impurity content, and no alpha-particle losses) lowered the COE, but none reduced the COE by more than $3.3 \%$. Broader density and temperature profiles and higher oxygen impurity content $(1.5 \%)$ increased the COE, but not by more than $6.4 \%$. Without any low-activation materials credits $(L S A=4)$, the COE increased by $15 \%$ to $77.1 \mathrm{mill} / \mathrm{kW}(\mathrm{e}) \mathrm{h}$.

The operating beta obtained for the reference case is $\langle\beta\rangle=4.7 \%$. If theory and experiments were to indicate that this value is not attainable, then a slightly larger reactor size and higher COE would be required. For example, if operation were limited to $\langle\beta\rangle=$ $3 \%$, then $R_{0}$ would be $6.4 \%$ larger $(7.0 \mathrm{~m})$ and the $\mathrm{COE}$ would be $5.6 \%$ higher $[70.7$ mill $/ \mathrm{kW}(\mathrm{e}) \mathrm{h}]$ than the reference CT6 values. Even lowering the $\langle\beta\rangle$ limit to $2 \%$ would only increase $R_{0}$ and the COE by $14.5 \%$. The variation of the COE and $\langle T\rangle$ with the imposed $\langle\beta\rangle$ limit is shown in Fig. 10. The unconstrained values for $\langle\beta\rangle$ and $\langle T\rangle$ are $4.7 \%$ and $6.84 \mathrm{keV}$. 


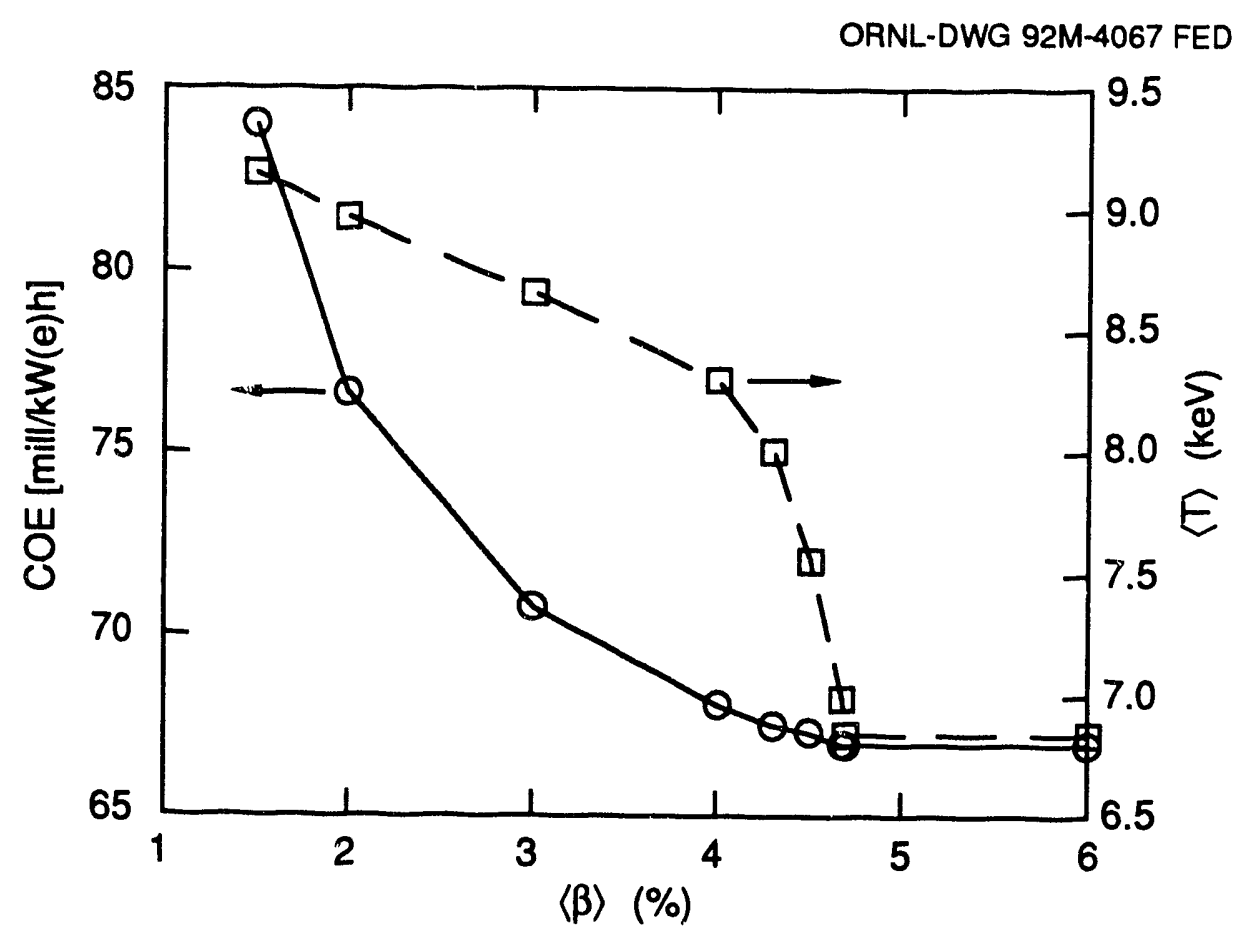

Fig. 10. Dependence of the COE and $\langle T\rangle$ on the imposed $\langle\beta\rangle$ limit.

\section{VI.D. Coil Configuration}

Two nine-field-per od Compact Torsatron (CT9) cases were analyzed to determine the sensitivity of the COE to the coil paramet - . The CT9 geometry is characterized by $A_{\mathrm{p}}=4.66, A_{\mathrm{c}}=3.24$, and $A_{\Delta}=8.60$. For the same assumptions as for the reference CT6 case, the CT9 COE is $70.4 \mathrm{mill} / \mathrm{kW}(\mathrm{e}) \mathrm{h}$. Although $R_{0}$ is $27 \%$ larger, the COE is only $5 \%$ higher than for the reference CT6 case because most of the costs that contribute to the COE are the same for the two cases. In addition, the CT9 case has $41 \%$ higher current density in the HF windings, which leads to lower costs for the coil systems and associated structure. For $B_{\max }=12 \mathrm{~T}$, the $\mathrm{COE}$ is $75.1 \mathrm{mill} / \mathrm{kW}(\mathrm{e}) \mathrm{h}$, only $3.2 \%$ higher than the corresponding CT6 case.

\section{VI.E. Scaling with Electrical Power Output}

A. reactor cases studied thus far have a net electrical power output $P_{\mathrm{E}}=1 \mathrm{GW}(\mathrm{e})$. Figure 11 shows the trade-off between confinement improvement and the thickness of the blanket under the inboard half of the helical windings as $P_{\mathrm{E}}$ is increased from $0.6 \mathrm{GW}(\mathrm{e})$ to $2 \mathrm{GW}(\mathrm{e})$ for two values of $\mathrm{H}^{\prime}(2$ and 2.5$)$ and $b_{\mathrm{i}}(0$ and $0.335 \mathrm{~m})$. Although power plants with $P_{\mathrm{E}}<1 \mathrm{GW}(\mathrm{e})$ are possible, significant improvements in reactor economics can be obtained for larger power plants. For the reference parameter choices in this study $\left(\mathrm{H}^{\prime}=2.5\right.$ and $\left.b_{\mathrm{i}}=0\right)$, increasing the electrical power output from $1 \mathrm{GW}(\mathrm{e})$ to $1.5 \mathrm{GW}(\mathrm{e})$ and $2 \mathrm{GW}(\mathrm{e})$ would reduce the $\mathrm{COE}$ by $18 \%$ and $25 \%$, respectively, if the costs of the reactor plant components continue to scale with power as they do at the 


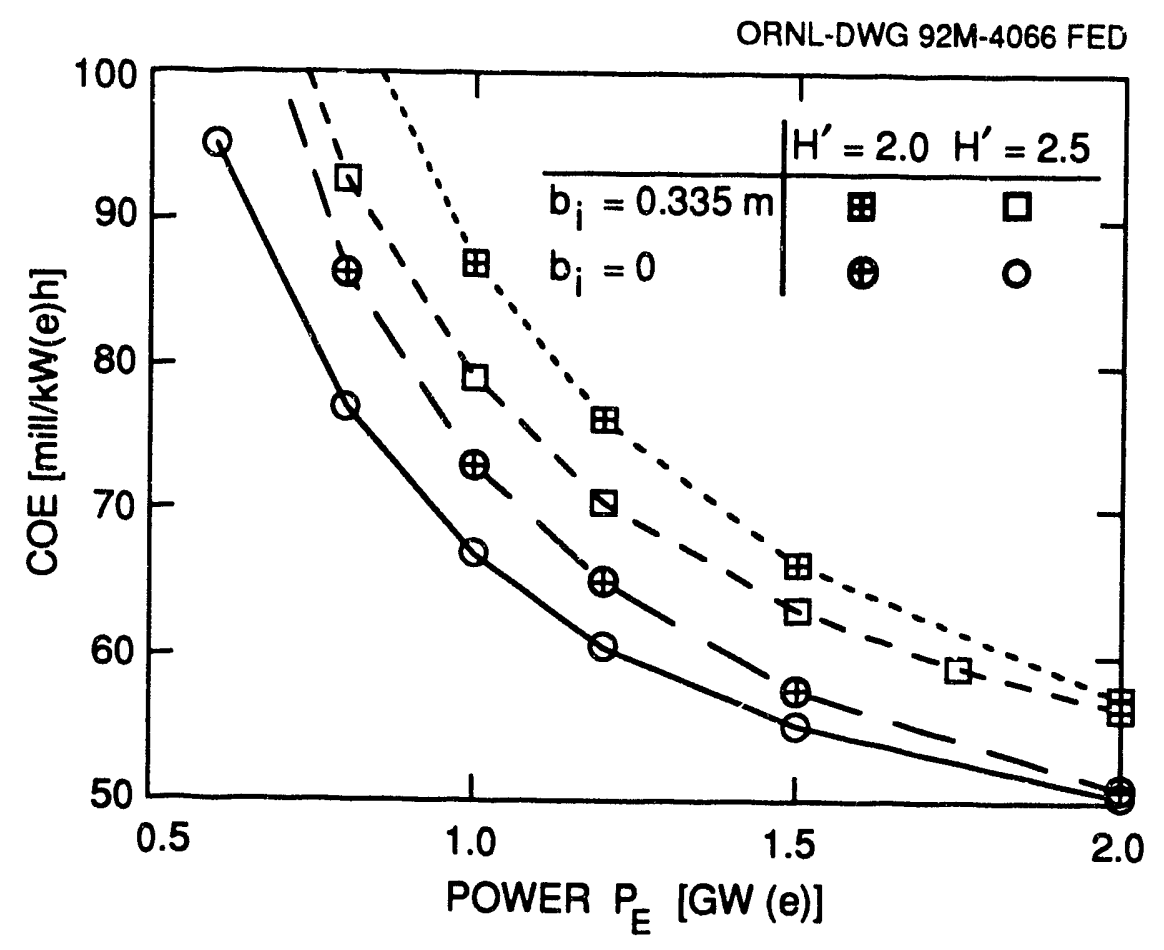

Fig. 11. Dependence of the COE on the net electrical power output.

1-GW(e) level. Even the relatively modest increase in $P_{\mathrm{E}}$ from $1 \mathrm{GW}(\mathrm{e})$ to $1.2 \mathrm{GW}(\mathrm{e})$ would reduce the COE by $10 \%$.

Combining approximate equations for the D-T fusion power, the conduction power loss, and the bremsstrahlung radiation loss for an ignited plasma gives $\langle\beta\rangle \propto P_{\mathrm{E}}\left(\mathrm{H}^{\prime}\right)^{5 / 2}$ for constant $\langle T\rangle$, which occurs for a wide range of parameters $\left[\mathrm{H}^{\prime}=1.1-3, P_{\mathrm{E}}=0.6\right.$ $2 \mathrm{GW}(\mathrm{e}), B_{\max }=8-18.3 \mathrm{~T}, k=0.5-4.5$, and $b_{\mathrm{i}}=0$ and $\left.0.335 \mathrm{~m}\right]$, as shown in Fig. 12 . When $\langle\beta\rangle$ is at a limit, $\langle T\rangle$ increases (also seen in Figs. 4 and 10 ).

\section{VI.F. Effect of Modularization}

The cases discussed thus far are based on continuous helical windings. Although used in this scoping study for simplicity in calculations and comparisons, continuous helical windings are not practical in a reactor in which it may be necessary to replace a coil, even if the coils are not as stressed as those in a tokamak reactor. As discussed in Sec. IV.A, helical windings may be modularized in the symmotron fashion ${ }^{34}$ or with several nonplanar TF coils per field period. The symmotron option is simulated in our calculations by adding VF coil segments that connect the beginning and end of each field period, and carry the full helical coil current, and extra VF coils to give the correct net VF coil currents. This approach is inefficient in that it requires additional coil mass, but it does preserve the open space between the helical windings for blankets and maintenance, which leads to smaller- $R_{0}$ reactors. The resulting COE is $67.5 \mathrm{mill} / \mathrm{kW}(\mathrm{e}) \mathrm{h}$, only $0.8 \%$ higher than for the reference CT6 case. 


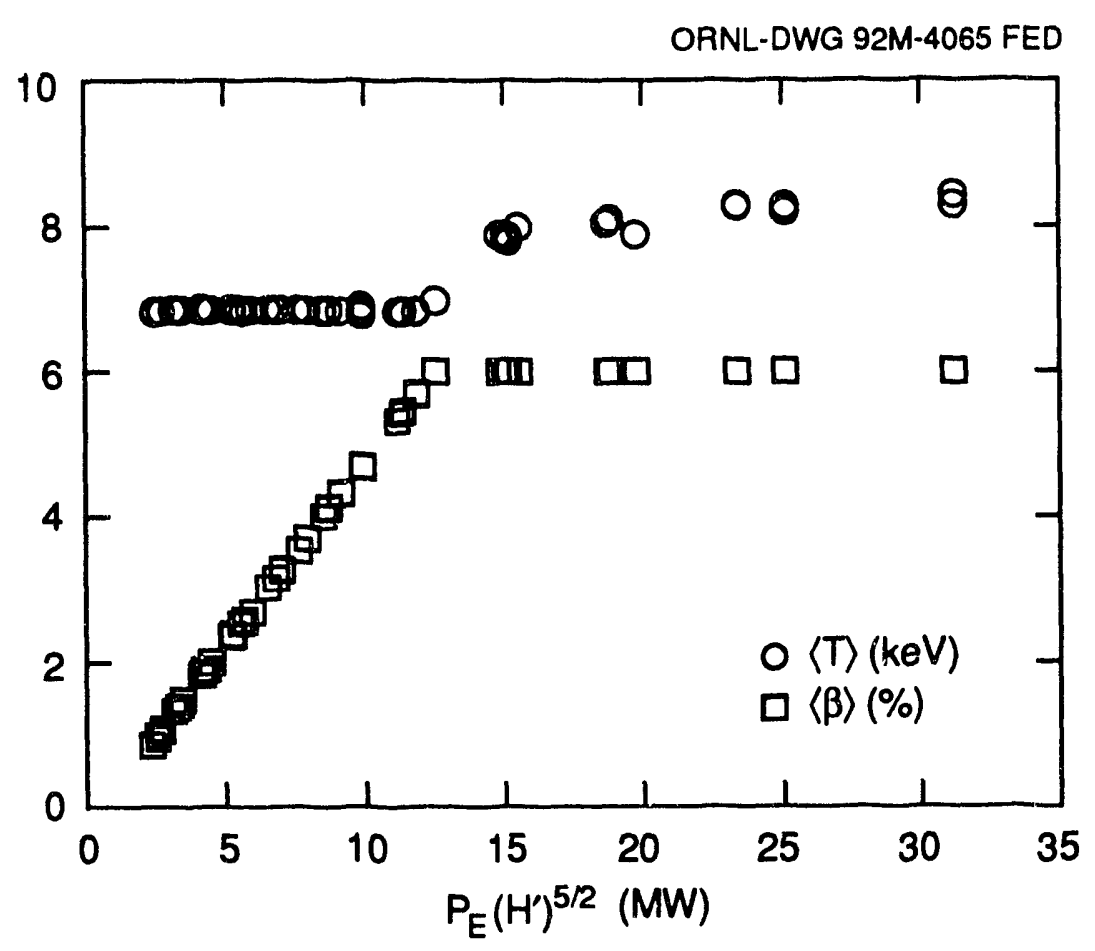

Fig. 12. Correlation of $\langle\beta\rangle$ and $\langle T\rangle$ with $P_{\mathrm{E}}$ and $\mathrm{H}^{\prime}$ for CT6 reactors.

Modularization using nonplanar TF coils ${ }^{35}$ is simulated by reducing the effective helical extent of the coils by a factor of two and eliminating the VF coils. The modular TF coil set produces the magnetic configuration more efficiently than a helical coil system that requires a VF coil with current in the direction opposite to that in the helical coils. However, there is no longer enough space between the nonplanar TF coils on the inboard half of the torus for the blanket segments, so the full blanket thickness $(0.67 \mathrm{~m})$ must be used everywhere on the inboard side. As a result, the major radius increases to $10.9 \mathrm{~m}$ and the COE to $92.7 \mathrm{mill} / \mathrm{kW}(\mathrm{e}) \mathrm{h}$. A CT6 reactor with the full blanket under the inboard half of the helical windings would have the same major radius and a COE of 94.3 mill/kW(e)h.

\section{CONCLUSIONS AND DISCUSSION}

Stellarators have significant operational advantages over tokamaks as ignited steadystate reactors. This scoping study shows that a torsatron reactor could also be competitive with a tokamak reactor in size and COE for a range of assumptions. The COE for the reference CT6 case, $18 \%$ lower than that for ARIES-I*, allows relaxing different assumptions and constraints while still keeping the COE less than that for ARIES-I*: $\mathrm{H}^{\circ}$ $>1.75$ for $b_{\mathrm{i}}=0$ and $\mathrm{H}^{\prime}>2.3$ for $b_{\mathrm{i}}=0.335 \mathrm{~m} ; \boldsymbol{B}_{\max }>9.6 \mathrm{~T} ; k>0.7$; or $P_{\mathrm{E}}>$ $0.75 \mathrm{GW}(\mathrm{e})$. Each of these options has its own advantages and various combinations are possible. The purpose of using the ARIES-I assumptions was to establish a common 
reference for comparison. Having established this reference, it is now appropriate to examine stellarator optimization based on different assumptions.

The CT6 torsatron configuration examined in this paper is not an "optimum" stellarator configuration for the reactor application; it is only one of the family of Compact Torsatron configurations ${ }^{33}$ that were obtained by maximizing the average radius of the last closed magnetic surface, subject to $\mathrm{MHD}$ constraints that maximized the $\langle\beta\rangle$ limit. While this is desirable for an experiment, it tends to minimize the critical distance between the plasma edge and the center of the helical winding, rather than maximizing it as needed for the reactor application. Although results to date are encouraging, further work on optimization of the coil configuration is needed in a number of areas to define an improved reference case: (1) improved low-aspect-ratio torsatron configurations with feasible modular coils that preserve the open helical structure of torsatrons and allow more room between the plasma edge and the center of the coils, which would reduce the size (and cost) of the reactor; (2) 3-D neutronics calculations to determine the required thickness of the side shields for the inboard coils, which determines the maximum allowable elongation fur the coils and hence their minimum radial depth; (3) shaping of the coil cross section, as is done in ATF and LHD, to allow more room at the sides of the coil for neutron shielding; (4) 3-D calculation of the maximum field on modular coils, which determines the maximum current density and stress in these coils; (5) optimization of the divertor geometry and its impact on the blanket design; and (6) 3-D calculations of the beta limits and ripple-induced transport for modular coil stellarators with optimized magnetic configurations and optimized plasma profiles. Also, more may be gained by lonking at cther stellarator reactor candidates. A serious effort in this direction is needed.

As stellarators approach the reactor collisionality regime, ripple-induced losses of thermal particles and compensating electric field effects should become more important. The simple zero-dimensional transport model used in this paper for comparison with ARIES-I can be replaced with a more refined 1-D stellarator transport model ${ }^{39}$ that calculates self-consistent radial profiles of the ion and electron temperatures and densities and the ambipolar radial electric field. ${ }^{40}$ These studies are under way.

Further inprovement in the outlook for torsatron reactors, and for stellarator reaciors in general, depends on establishing the physics basis needed for reactor extrapolation and on furtiler optimizing the stellarator coil configuration. Present stellarators $\mathrm{s}^{41}$ can develop much of the physics basis needed for stellarator optimization. ATF (Ref. 7) was designed to study $\beta$ optimization and confinement improvement through access to the second stability regime. Wendelstein VII-AS (Ref. 42) was designed to study confinement improvement through reduction of the Pfirsch-Schlüter current. The Compact Helical System (Ref. 43) was designed to study lower aspect ratio. DIII-D-scale stellarators with superconducting coils that can demonstrate true steady-state operation, effective control of particles and impurities with divertors, and significantly higher plasma parameters $(\beta$, $T_{\mathrm{i}}, n \tau_{E} T_{\mathrm{i}}$ ) are now under construction in Japan (LHD, Ref. 13) and in the design and approval phase in Germany (Wendelstein VII-X, Ref. 14). 


\section{ACKNOWLEDGMENTS}

The authors acknowledge useful discussions with R. L. Miller, Y-K. M. Peng, C. G. Bathke, J. A. Rome, and J. Sheffield, and the assistance of M. J. Crouse. 


\section{REFERENCES}

1. R. W. CONN and F. NAJMABADI, "Visions of the Future, A Program in Tokamak Reactor Studies," UCLA-PPG-1201, University of California, Los Angeles (December 1987).

2. D. E. BALDWIN et al., "U.S. National Review of the ITER Conceptual Design Activity," University of Texas, Austin, March 1991 (unpublished).

3. C. GOURDON, D. MARTY, E. K. MASCHKE, and J. TOUCHE, "The Torsatron Without Toroidal Field Coils as a Solution of the Divertor Problem," Nucl. Fusion, 11, 161 (1971).

4. N. OHYABU, N. NODA, J. HANTAO, et al., "Helical Divertor in the Large Helical Device," NIFS-144, National Institute for Fusion Science, Nagoya, Japan (May 1992).

5. S. L. PAINTER and J. F. LYON, "Alpha-Particle Losses in Compact Torsatron Reactors," Fusion Technol., 16, 157 (1989).

6. M. MURAKAMI, B. A. CARRERAS, L. R. BAYLOR, et al., "Bootstrap-Current Experiments in a Toroidal Plasma-Confinement Device," Phys. Rev. Lett., 66, 707 (1991).

7. J. F. LYON, B. A. CARRERAS, K. K. CHIPLEY, et al., "The Advanced Toroidal Facility," Fusion Technol., 10, 179 (1986).

8. J. H. HARRIS, M. MURAKAMI, B. A. CARRERAS, et al., "Second Stability in the ATF Torsatron," Phys. Rev. Lett., 63, 1249 (1989).

9. R. J. GOLDSTON, H. BIGLARI, G. W. HAMMETT, et al., " $E \times B / B^{2}$ vs. $v \| \widetilde{B} / B$ as the Cause of Transport in Tokamaks," Bull. Am. Phys. Soc., 34, 1964 (1989).

10. M. MURAKAMI, T. S. BIGELOW, B. A. CARRERAS, et al., "Transport Studies Using Modulation of Dimensionless Parameters in the Advanced Toroidal Facility," Proc. 1992 Int. Conf. Plasma Physics, Innsbruck, Austria, 1992, Vol. 16C, Part I, p. 521, European Physical Society (1992); see also M. MURAKAMI, T. S. BIGELOW, J. B. WILGEN, et al., "Dimensionless Scaling of Confinement in ATF," paper IAEA-CN-56/C-1-1 presented at the 14th International Conference on Plasma Physics and Controlled Nuclear Fusion Research, Würzburg, Germany, 1992.

11. S. KAYE et al., private communication, 1992.

12. J. F. LYON, "Near-Term Directions in the World Stellarator Program," Fusion Technol., 17, 19 (1990).

13. A. IYYOSHI, M. FUJIWARA, O. MOTOJIMA, N. OHYABU, and K. YAMAZAKI, "Design Study for the Large Helical Device," Fusion Technol., 17, 169 (1990).

14. C. BEIDLER, G. GRIEGER, F. HERRNEGGER, et al., "Physics and Engineering Design for Wendelstein VII-X," Fusion Technol., 17, 148 (1990).

15. G. GRIEGER, E. HARMEYER, W. LOTZ, et al., "Modular Stellarator Reactors and Plans for Wendelstein 7-X," Fusion Technol., 21, 1767 (1992). 
16. Y. KAZAWA, Y. ITOU, S. SUZUKI, et al., "Conceptual Design Study of Heliotron Reactors (F2, I)," Proc. Int. Stellarator/Heliotron Workshop, Kyoto, 1986, p. 540, PPLK-6, Kyoto University (1986).

17. E. D. VOLKOV, A. V. GEORGIEVSKIJ, Yu. K. KUZNETSOV, et al., "Fundamental Conceptions of a Reactor-Torsatron with an Additional Longitudinal Field," Proc. 4th IAEA Technical Committee Mtg. Fusion Reactor Design and Technology 1986, Yalta, 1986, Vol. 1, p. 393, International Atomic Energy Agency, Vienna (1987).

18. J. F. LYON, B. A. CARRERAS, V. E. LYNCH, J. S. TOLLIVER, and I. N. SVIATOSLAVSKY, "Compact Torsatron Reactors," Fusion Technol., 15, 1401 (1989).

19. J. HÜBENER and W. MAURER, "General Design of a Modular Stellarator Reactor," Proc. 4th IAEA Technical Committee Mtg. Fusion Reactor Design and Technology 1986, Yalta, 1986, Vol. 1, p. 333, International Atomic Energy Agency, Vienna (1987).

20. R. L. MILLER, R. A. KRAKOWSKI, and the ARIES TEAM, "Options and Optimizations for Tokamak Reactors: ARIES," Fusion Technol., 19, 802 (1991).

21. F. NAJMABADI, R. W. CONN, and the ARIES TEAM, "The ARIES-I Tokamak Reactor Study," Fusion Technol., 19, 783 (1991).

22. F. NAJMABADI, R. W. CONN, and the ARIES TEAM, "The ARIES-I Tokamak Reactor Study," UCLA-PPG-1323, University of California, Los Angeles (1992).

23. R. L. MILLE, Los Alamos National Laboratory, private communication, March 1992.

24. F. NAJMABADI, R. W. CONN, and the ARIES TEAM, "The ARIES Tokamak Fusion Reactor Study," Proc. 13th Symp. Fusion Engineering, Knoxville, 1989, Vol. 2, p. 1021, IEEE, New York (1989).

25. J. G. DELENE, "Updated Comparison of Economics of Fusion Reactors with Advanced Fission Reactors," Fusion Technol., 19, 807 (1991).

26. R. A. KRAKOWSKI, "Insights from Reactor Studies" (unpublished), March 1992.

27. J. SCHWARTZ, J. R. MILLER, and J. E. C. WILLIAMS, "TF Overall Current Density Scaling" (unpublished), November 1988.

28. S. L. PAINTER, "Performance Analysis and Parametric Optimization Study of Torsatron Fusion Reactors," Ph.D. thesis, University of Tennessee (1990).

29. W. D. CAIN, "MAGFOR: A Magnetics Code to Calculate Fields and Forces in Twisted Helical Coils of Constant Cross Section," Proc. IOth Symp. Fusion Engineering, Philadelphia, 1983, Vol. 2, p. 1223, IEEE, New York (1983).

30. J. A. ROME, R. H. FOWLER, and G. A. EMMERT, "Divertor Calculations for Stellarators," Proc. Int. Stellarator/Heliotron Workshop, Kyoto, 1986, p. 491, PPLK-6, Kyoto University (1986).

31. S. SUDO, Y. TAKEIRI, H. ZUSHI, et al., "Scalings of Energy Confinement and Density Limit in Stellarator/Heliotron Devices," Nucl. Fusion, 30, 11 (1990). 
32. K. LACKNER and N. A. O. GOTTARDI, "Tokamak Confinement in Relation to Plateau Scaling," Nucl. Fusion, 30, 767 (1990); see also A. WELLER, R. BRAKEL, R. BURHENN, et al., "Optimum Confinement in the Wendelstein 7-AS Stellarator," Plasma Phys. Controlled Fusion, 33, 1559 (1991).

33. B. A. CARRERAS, N. DOMINGUEZ, L. GARCIA, et al., "Low-Aspect-Ratio Torsatron Configurations," Nucl. Fusion, 28, 1195 (1988).

34. J. F. LYON, B. A. CARRERAS, J. H. HARRIS, et al., "Stellarator Physics Evaluation Studies," Proc. 9th Int. Conf. Plasma Physics and Controlled Nuclear Fusion Research, Baltimore, Maryland, 1982, Vol. 3, p. 115, International Atomic Energy Agency, Vienna (1983); see also L. GARCIA, B. A. CARRERAS, J. H. HARRIS, et al., "Equilibrium Studies for Low-Aspect-Ratio Torsatrons," Nucl. Fusion, 24, 115 (1984).

35. P. MERKEL, "Solution of Stellarator Boundary Value Problems with External Currents," Nucl. Fusion, 27, 867 (1987).

36. V. ERCKMANN, R. BRAKEL, R. BURHENN, et al., "H-Mode Like Transitions in the W 7-AS Stellarator with High Power $140 \mathrm{GHz}$ ECRH," presented at the 14th International Conference on Plasma Physics and Controlled Nuclear Fusion Research, Würzburg, Germany, 1992.

37. K. TOI, S. OKAMURA, H. IGUCHI, et al., "Formation of $\mathrm{H}$-mode Like Transport Barrier in the CHS Heliotron/Torsatron," presented at the 14th International Conference on Plasma Physics and Controlled Nuclear Fusion Research, Würzburg, Germany, 1992.

38. B. A. CARRERAS, "Anomalous Transport in the Second Stability Regime," Comments Plasma Phys. Controlled Fusion, 12, 35 (1988).

39. S. L. PAINTER and J. F. LYON, "Transport Analysis of Stellarator Reactors," Nucl. Fusion 31, 2271 (1991).

40. S. L. PAINTER and P. N. STEVENS, "Design-Oriented Methods for OneDimensional Analysis of Fusion Reactor Plasma Performance," Fusion Technol., 21, 1617 (1992).

41. J. F. LYON, "Review of Recent Stellarator Results in the U.S.A., the U.S.S.R., and Japan," Plasma Phys. Controlled Fusion, 32, 1041 (1990).

42. J. SAPPER and H. RENNER, "Stellarator W VII-AS: Physics and Engineering Design," Fusion Technol., 17, 62 (1990).

43. K. NISHIMURA, K. MATSUOKA, M. FUJIWARA, et al., "Compact Helical Physics and Engineering Design," Fusion Technol., 17, 86 (1990). 
ORNL/TM-12189

Dist. Category UC-420

\section{INTERNAL DISTRIBUTION}

1. Director, ORNL Fusion Energy Division

2. C. C. Baker

3. M. J. Saltmarsh

4. L. A. Berry

5. B. A. Carreras

6. R. A. Dory

7. J. L. Dunlap

8. H. H. Haselton

9. M. S. Lubell

10. T. E. Shannon

11. R. P. Leinius

12-13. Laboratory Records Department

14. Laboratory Records, ORNL-RC

15-16. Central Research Library
17. Document Reference Section

18. Fusion Energy Division Library

19-20. Engineering Technology/Fusion Energy Division Publications Office

21. ORNi. Patent Office

22-61. J. F. Lyon

62. W. Fulkerson

63. J. H. Harris

64. S. P. Hirshman

65. P. K. Mioduszewski

66. M. Murakami

67. Y-K. M. Peng

68. J. A. Rome

69. N. A. Uckan

\section{EXTERNAL DISTRIBUTION}

70. S. L. Painter, Research School of Physical Sciences, Australian National University, P.O. Box 4, Canberra, A.C.T. 2601, Australia

71. Office of the Assistant Manager for Energy Research and Development, U.S. Department of Energy Field Office, Oak Ridge, P.O. Box 2000, Oak Ridge, TN 37831

72. N. A. Davies, Director, Office of Fusion Energy, Office of Energy Research, ER-50 Germantown, U.S. Department of Energy, Washington, DC 20545

73. M. Roberts, International Programs, Office of Fusion Energy, Office of Energy Research, ER-52 Germantown, U.S. Department of Energy. Washington, DC 20545

74. D. E. Baldwin, Lawrence Liverm.ore National Laboratory, P.O. Box 5511, Livermore, CA 94550

75. R. W. Conn, Mechanical, Aerospace, and Nuclear Engineering Department, 6291 Boelter Hz.ll, University of California, Los Angeles, CA $90024-1597$

76. P. C. Liewer, MS 138-208, Jet Propulsion Laboratory, 4800 Oak Grove Drive, Pasadena, CA 91109

77. R. Parker, Plasma Fusion Center, Massachusetts Institute of Technology, 167 Albany St., NW16288, Cambridge, MA 02139

78. K. I. Thomassen, L-637, Lawrence Livermore National Laboratory, P.O. Box 5511, Livermore, CA 94550

79. J. D. Callen, Department of Nuclear Engineering, University of Wisconsin, Madison, WI 53706 1687

80. S. O. Dean, Fusion Power Associates, Inc., 2 Professional Drive, Suite 248, Gaithersburg, MD 20879

81. H. K. Forsen, Bechtel Group, Inc., Research Engineering, P.O. Box 3965, San Francisco, CA 94119

82. R. W. Gould, Department of Applied Physics, California Institute of Technology, Pasadena, CA 91125 
83. R. A. Gross, Plasma Research Laboratory, Columbia University, New York, NY 10027

84. R. J. Hawryluk, Princeton Plasma Physics Laboratory, P.O. Box 451, Princeton, NJ 08543

85. D. M. Meade, Princeton Plasma Physics Laboratory, P.O. Box 451, Princeton, NJ 08543

86. W. M. Stacey, School of Nuclear Engineering and Health Physics, Georgia Institute of Technology, Atlanta, GA 30332

87. D. Steiner, Nuclear Engineering Department, NES Building, Tibbetts Avenue, Rensselaer Polytechnic Institute, Troy, NY 12181

88. R. Varma, Physical Research Laboratory, Navrangpura, Ahmedabad 380009, India

89. Bibliothek, Max-Planck Institut für Plasmaphysik, Boltzmannstrasse 2, D-8046 Garching, Federal Republic of Germany

90. Bibliothek, Institut für Plasmaphysik, KFA Jülich GmbH, Postfach 1913, D-5170 Jülich, Federal Republic of Germany

91. Bibliothek, KfK Karlsruhe GmbH, Postfach 3640, D-7500 Karlsruhe 1, Federal Republic of Germany

92. Bibliotheque, Centre de Recherches en Physique des Plasmas, Ecole Polytechnique Fédérale de Lausanne, 21 Avenue des Bains, CH-1007 Lausanne, Switzerland

93. R. Aymar, CEN/Cadarache, Departement de Recherches sur la Fusion Contrôlée, F-13108 SaintPaul-lez-Durance Cedex, France

94. Bibliothèque, CEN/Cadarache, F-13108 Saint-Paul-lez-Durance Cedex, France

95. Library, JET Joint Undertaking, Abingdon, Oxfordshire OX14 3EA, England

96. Library, FOM-Instituut voor Plasmafysica, Rijnhuizen, Edisonbaan 14, 3439 MN Nieuwegein, The Netherlands

97. Library, National Institute for Fusion Science, Chikusa-ku, Nagoya 464-01, Japan

98. Library, International Centre for Theoretical Physics, P.O. Box 586, I-34100 Trieste, Italy

99. Library, Centro Ricerche Energia Frascati, C.P. 65, I-00044 Frascati (Roma), Italy

100. Library, Plasma Physics Laboratory, Kyoto University, Gokasho, Uji, Kyoto 611, Japan

101. Plasma Research Laboratory, Australian National University, P.O. Box 4, Canberra, A.C.T. 2601, Australia

102. Library, Japan Atomic Energy Research Institute, Naka Fusion Research Establishment, 801-1 Mukoyama, Naka-machi, Naka-gun, Ibaraki-ken, Japan

103. G. A. Eliseev, I. V. Kurchatov Institute of Atomic Energy, P.O. Box 3402, 123182 Moscow, Russia

104. V. A. Glukhikh, Scientific-Research Institute of Electro-Physical Apparatus, 188631 St. Petersburg, Russia

105. I. Shpigel, Institute of General Physics, Academy of Sciences, Ulitsa Vavilova 38, Moscow, Russia

106. D. D. Ryutov, Institute of Nuclear Physics, Siberian Branch of the Academy of Sciences Sovetskaya St. 5, 630090 Novosibirsk, Russia

107. O. Pavlichenko, Kharkov Physical-Technical Institute, Academical St. 1, 310108 Kharkov, Ukraine

108. Deputy Director, Southwestern Institute of Physics, P.O. Box 15, Leshan, Sichuan, China (PRC)

109. Director, The Institute of Plasma Physics, P.O. Box 1126, Hefei, Anhui, China (PRC)

110. R. A. Blanken, Experimental Plasma Physics Research Branch, Division of Applied Plasma Physics, Office of Energy Research, ER-542, Germantown, U.S. Department of Energy, Washington, DC 20545

111. R. A. E. Bolton, IREQ Hydro-Quebec Research Institute, 1800 Montée-Ste.-Julie, Varennes, P.Q. JOL 2P0, Canada

112. D. H. Crandall, Experimental Plasma Physics Research Branch, Division of Applied Plasma Physics, Office of Energy Research, ER-542, Germantown, U.S. Department of Energy, Washington, DC 20545

113. R. L. Freeman, General Atomics, P. O. Box 85608, San Diego, CA 92138-5608

114. K. W. Gentle, RLM 11.222, Institute for Fusion Studies, University of Texas, Austin, TX 78712 
115. R. J. Goldston, Plasma Physics Laboratory, Princeton University, P.O. Box 451, Princeton, NJ 08543

116. J. C. Hosea, Plasma Physics Laboratory, Princeton University, P.O. Box 451, Princeton, NJ 08543

117. D. Markevich, Division of Confinement Systems, Office of Energy Research, ER-55, Germantown, U.S. Department of Energy, Washington, DC 20545

118. R. H. McKnight, Experimental Plasma Physics Research Branch, Division of Applied Plasma Physics, Office of Energy Research, ER-542, Germantown, U.S. Department of Energy, Washington, DC 20545

119. E. Oktay, Division of Confinement Systems, Office of Energy Research, ER-55, Germantown, U.S. Department of Energy, Washington, DC 20545

120. W. L. Sadowski, Fusion Theory and Computer Services Branch, Division of Applied Plasma Physics, Office of Energy Research, ER-541, Germantown, U.S. Department of Energy, Washington, DC 20545

121. J. W. Willis, Division of Confinement Systems, Office of Energy Research, ER-55, Germantown, U.S. Department of Energy, Washington, DC 20545

122. A. P. Navarro, Division de Fusion, CIEMAT, Avenida Complutense 22, E-28040 Madrid, Spain

123. Laboratory for Plasma and Fusion Studies, Department of Nuclear Engineering, Seoul National University, Shinrim-dong, Gwanak-ku, Seoul 151, Korea

124. Laboratorio Associado de Plasma, Instituto Nacional de Pesquisas Espaciais, Caixa Postal 515, 122201, Sao Jose dos Campos, SP, Brazil

125. J. L. Johnson, Plasma Physics Laboratory, Princeton University, P.O. Box 451, Princeton, NJ 08543

126. L. M. Kovrizhnykh, Institute of General Physics, Academy of Sciences, Ulitsa Vavilova 38, 117924 Moscow, Russia

127. O. Motojima, National Institute for Fusion Science, Chikusa-ku, Nagoya 464-01, Japan

128. S. Okamura, National Institute for Fusion Science, Chikusa-ku, Nagoya 464-01, Japan

129. V. D. Shafranov, I. V. Kurchatov Institute of Atomic Energy, P.O. Box 3402, 123182 Moscow, Russia

130. J. L. Shohet, Torsatron/Stellarator Laboratory, University of Wisconsin, Madison, WI 53706

131. H. Wobig, Max-Planck Institut für Plasmaphysik, Boltzmannstrasse 2, D-8046 Garching, Federal Republic of Germany

132. F. Najmabadi, 44-139 Engineering IV, Institute of Plasma and Fusion Research, University of California, Los Angeles, CA $90024-1597$

133. R. A. Krakowski, MS F607, Los Alamos National Laboratory, Los Alamos, NM 87545

134. R. L. Miller, MS F607, Los Alamos National Laboratory, Los Alamcs, NM 87545

135. S. R. Martin, U.S. Department of Energy, Oak Ridge Field Office, Oak Ridge, TN 37831-6269

136. W. F. Dove, Division of Applied Plasma Physics, Office of Fusion Energy, Office of Er.crgy Research, ER-543 Germantown, U.S. Department of Energy, Washington, DC 20: 75

137. S. Berk, Office of Fusion Energy, Office of Energy Research, ER-533 Germantown, U.S. Department of Energy, Washington, DC 20545

138. F. Perkins, Plasma Physics Laboratory, Princeton University, P.O. Box 451, Princeton, NJ 08543

139. N. H. Lazar, TRW Defense and Space Systems, Room 1280, Bldg. 01, One Space Park, Redondo Beach, CA 90278

140. T. Obiki, Plasma Physics Laboratory, Kyoto University, Gokasho, Uji, Kyoto 611, Japan

141. A. Iyoshi, National Institute for Fusion Science, Chikusa-ku, Nagoya 464-01, Japan

142. G. Grieger, Max-Planck Institut für Plasmaphysik, Boltzmannstrasse 2, D-8046 Garching, Federal Republic of Germany

143. K. Matsuoka, National Institute for Fusion Science, Chikusa-ku, Nagoya 464-01, Japan

144. R. E. Siemon, MS H854, Los Alamos National Laboratory, Los Alamos, NM 87545

145. R. F. Gandy, Physics Department, Auburn University, Auburm, AL 36849-351 1 
146. D. T. Anderson, University of Wisconsin, Madison, WI 53706

147. M. Wakatani, Plasma Physics Laboratory, Kyoto University, Gokasho, Uji, Kyoto 611, Japan

148. F. Wagner, Max-Planck Institut für Plasmaphysik, Boltzmannstrasse 2, D-8046 Garching, Federal Republic of Germany

129-168. Given distribution as shown in DOE/OSTI-4500, Magnetic Fusion Energy (Category Distribution UC-420, Magnetic Fusion Energy) 

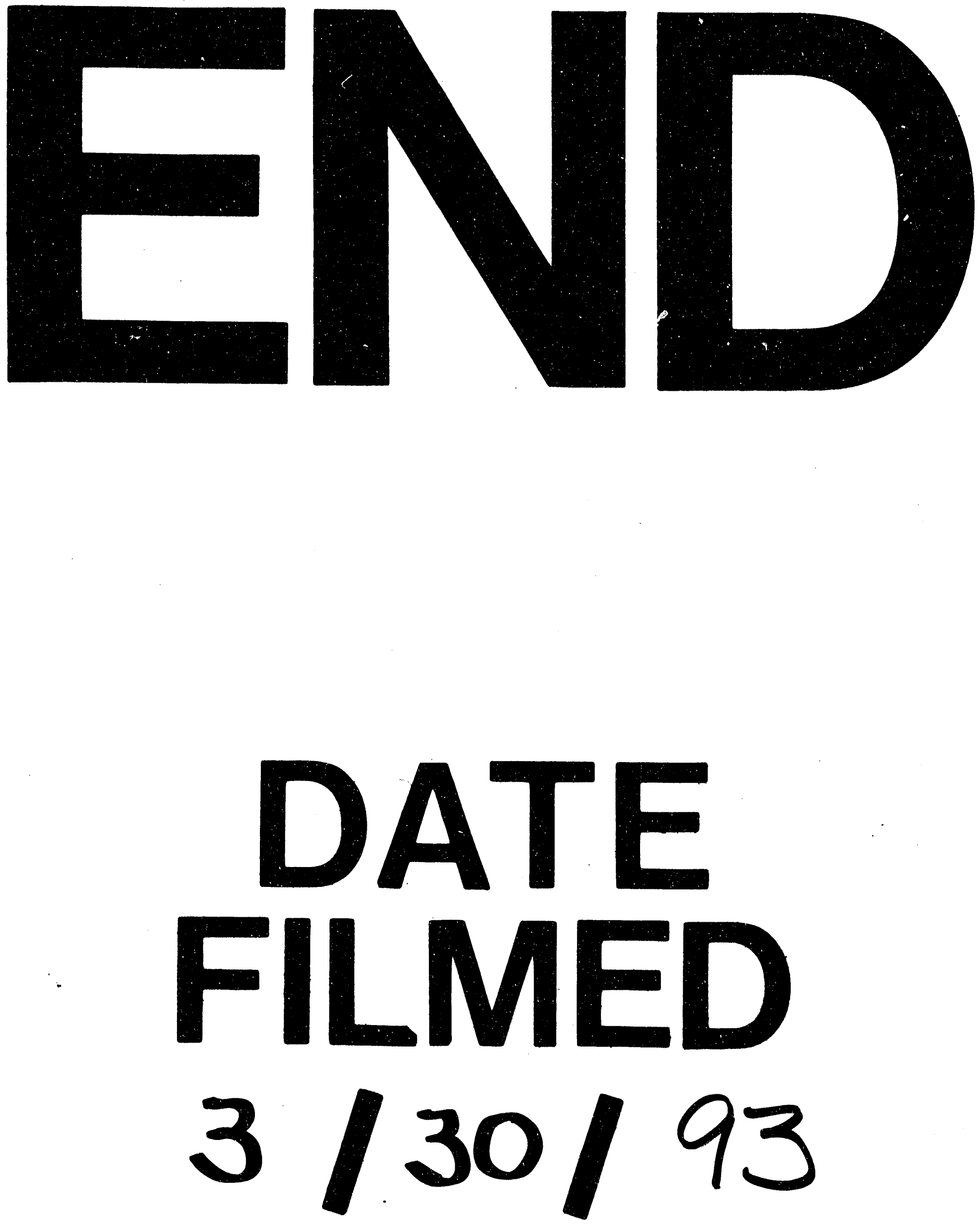
